\title{
Consensus guidelines on the optimal management in interventional EUS procedures: results from the Asian EUS group RAND/UCLA expert panel
}

\author{
Anthony Y B Teoh, ${ }^{1}$ Vinay Dhir, ${ }^{2}$ Mitsuhiro Kida, ${ }^{3}$ Ichiro Yasuda, ${ }^{4}$ Zhen Dong Jin, ${ }^{5}$ \\ Dong Wan Seo, ${ }^{6}$ Majid Almadi, ${ }^{7}$ Tiing Leong Ang, ${ }^{8}$ Kazuo Hara ${ }_{1}^{9}$ Ida Hilmi, ${ }^{10}$ \\ Takao Itoi, ${ }^{11}$ Sundeep Lakhtakia, ${ }^{12}$ Koji Matsuda, ${ }^{13}$ Nonthalee Pausawasdi, ${ }^{14}$ \\ Rajesh Puri, ${ }_{15}^{15}$ Raymond S Tang, ${ }^{16}$ Hsiu-Po Wang, ${ }^{17}$ Ai Ming Yang ${ }_{1}^{18}$ Robert Hawes, ${ }^{19}$ \\ Shyam Varadarajulu, ${ }^{19}$ Kenjiro Yasuda, ${ }^{20}$ Lawrence Khek Yu Ho ${ }^{21}$
}

For numbered affiliations see end of article.

\section{Correspondence to}

Professor Anthony Y B Teoh, Department of Surgery, The Chinese University of Hong Kong, Prince of Wales Hospital, Shatin, New Territories, Hong Kong SAR, China; anthonyteoh@surgery.cuhk. edu.hk

Received 18 April 2017 Revised 22 December 2017 Accepted 17 January 2018 Published Online First 20 February 2018
Check for updates

To cite: Teoh AYB, Dhir V, Kida $\mathrm{M}$, et al. Gut

2018:67:1209-1228.

\section{ABSTRACT}

Objectives Interventional endoscopic ultrasonography (EUS) procedures are gaining popularity and the most commonly performed procedures include EUS-guided drainage of pancreatic pseudocyst, EUS-guided biliary drainage, EUS-guided pancreatic duct drainage and EUSguided celiac plexus ablation. The aim of this paper is to formulate a set of practice guidelines addressing various aspects of the above procedures.

Methods Formulation of the guidelines was based on the best scientific evidence available. The RAND/UCLA appropriateness methodology (RAM) was used. Panellists recruited comprised experts in surgery, interventional EUS, interventional radiology and oncology from 11 countries. Between June 2014 and October 2016, the panellists met in meetings to discuss and vote on the clinical scenarios for each of the interventional EUS procedures in question.

Results A total of 15 statements on EUS-guided drainage of pancreatic pseudocyst, 15 statements on EUS-guided biliary drainage, 12 statements on EUSguided pancreatic duct drainage and 14 statements on EUS-guided celiac plexus ablation were formulated. The statements addressed the indications for the procedures, technical aspects, pre- and post-procedural management, management of complications, and competency and training in the procedures. All statements except one were found to be appropriate. Randomised studies to address clinical questions in a number of aspects of the procedures are urgently required.

Conclusions The current guidelines on interventional EUS procedures are the first published by an endoscopic society. These guidelines provide an in-depth review of the current evidence and standardise the management of the procedures.

\section{INTRODUCTION}

Interventional endoscopic ultrasonographic (EUS) procedures have undergone tremendous development over the past two decades. The types of procedures have expanded from drainage of pancreatic fluid collections to tumour ablations, gallbladder drainage and enteric anastomosis. With the aim of providing a road map to guide industry and investigators on how to facilitate implementation of therapeutic EUS into clinical practice, the EUS
Working Group identified five interventions as high priority for research to increase their adoption in clinical practice in 2008. These procedures were celiac plexus neurolysis and block, drainage of pancreatic fluid collections, hepaticogastrostomy, choledochoduodenostomy and ablation of pancreatic-cystic neoplasm. ${ }^{1}$

Since then, large numbers of publications have addressed various aspects of EUS-guided interventional procedures. The procedural techniques have evolved and EUS-specific devices aimed at improving the ease and safety of performing the procedures have also emerged. In order to further promote the safe adoption of these techniques, a set of practice guidelines addressing these changes in the most commonly performed interventional EUS procedures is required. The guidelines should address the indications for the procedures, technical aspects, pre- and post-procedural management, management of complications and competency and training. The aim of the current paper is to formulate these guidelines in a scientific manner based on the best available evidence.

\section{METHODS}

The procedures examined in the current guidelines were chosen by the Asian EUS group as they represent the most commonly performed interventional EUS procedures. They include EUS-guided drainage of pancreatic pseudocyst, EUS-guided biliary drainage (EUS-BD), EUS-guided pancreatic duct drainage (EUS-PD) and EUS-guided celiac plexus ablation. The Asian EUS group comprises expert endosonographers from 18 countries in Asia with a primary focus on education and research in EUS. Formulation of the guidelines was based on the best scientific evidence available. However, the panel acknowledges the fact that evidence may be lacking in certain areas of the concerned procedure. Thus, the RAND/UCLA (research and development) Corporation and UCLA (University of California-Los Angeles) appropriateness methodology (RAM) was used, as it could combine the best scientific evidence with the collective judgement of experts to formulate the statements. After completion of the statements, the guidelines 


\section{Review and summarise the literature for processes of care}

2. Expert panel members individually score scenarios for appropriateness

3. Data analysed to guide expert panel discussion

4. Expert panel meeting to discuss areas of disagreement regarding processes of care in the scenarios

5. Re-scoring of scenarios for appropriateness and necessity

6. Creation of summary statements

7. Scoring of summary statements for appropriateness and necessity

Figure 1 The RAM process.

were then sent to the advisors of the group for comments and feedback.

RAM is a method of group consensus developed in the 1980s by RAND and UCLA. It is a well-established method for creating guidelines for over 50 conditions and procedures. ${ }^{2}$ RAM enables the measurement of overuse or underuse of medical and surgical procedures and has been applied to the development of practice guidelines. ${ }^{3-8}$ In RAM, the concept of appropriateness refers to the relative weight of the benefits and harms of a medical or surgical intervention. An appropriate procedure is one in which 'the expected health benefit exceeds the expected negative consequences by a sufficiently wide margin that the procedure is worth doing, exclusive of cost'. The method was driven by the concern that the increasing complexity of medical care was resulting in some patients not undergoing procedures that they needed, and others undergoing procedures that they did not need. The rationale behind the method is that randomised clinical trials-the 'gold standard' for evidence-based medicineoften are either not available or cannot provide evidence at a level of detail sufficient to apply to the wide range of patients seen in everyday clinical practice. Nevertheless, physicians will still need to make decisions every day about when to apply them. Consequently, it was believed a method was needed that would combine the best available scientific evidence with the collective judgement of experts to yield a statement regarding the appropriateness of performing a procedure at the level of patient-specific symptoms, medical history and test results. Measurement of necessity was not performed for these guidelines.

The RAM process is shown in figure 1. The process involves: (1) performing a literature search to determine the evidence for processes of care; (2) creating clinical scenarios or statements for treatment options; (3) assembling an expert panel to grade the appropriateness of treatments; and (4) evaluating all appropriate processes for necessity. ${ }^{9}$ A leader was assigned to each of the interventional EUS procedures in question. A detailed literature review was conducted to synthesise the latest evidence of a broad range of peri-procedural processes involved in the interventional EUS procedure in question by the respective leaders. ${ }^{10} 11$ Electronic literature searches were conducted using PubMed, Medline and Embase from 1 January 1992 to 31 December
2016. Searches were performed under the following aspects to generate the statements: indications for the procedure, the optimal approach, pre-procedural evaluations and preparations, procedural considerations, adjunctive treatments, management of complications, competency and training. Articles were selected using $\mathrm{MeSH}$ headings and text words related to the interventional procedure. For pseudocyst drainage, the text words used were: pancreatic pseudocyst, pseudocyst drainage, cystogastrostomy, cystojejunostomy, transmural pseudocyst drainage, transpapillary pseudocyst drainage and percutaneous pseudocyst drainage; for biliary drainage, the following text words were used: EUS-guided biliary drainage, percutaneous biliary drainage, transluminal biliary drainage, choledochoduodenostomy and hepaticogastrostomy; for pancreatic duct drainage the text words used were: EUS-guided pancreatic duct drainage, pancreatic ducts and pancreatic duct intervention; and for celiac plexus ablations the following search terms were used: endoscopic ultrasound, celiac plexus block, celiac plexus neurolysis, chronic pancreatitis and pancreatic cancer. Only English language studies involving the concerned treatment approaches were included and comparative studies were preferred. Reference lists from eligible trials were also checked to locate missing publications. The titles of the articles and abstracts located were evaluated by the leader of the group and a member of the procedure. Where the article fulfilled the selection criterion, a copy of the full manuscript was obtained. Full manuscripts were then reviewed and a final decision was made about inclusion. Studies published only in abstract form, conference abstracts, symposium proceedings and case reports were not eligible for inclusion. Any disagreements were resolved by consensus. The same methodology was used for each interventional procedure in question for this manuscript and several reviews have also been published by the Asian EUS group. ${ }^{10-13}$

Panellists on the voting panel were recruited through solicitation of nominations from the Asian EUS group which comprises experts in surgery, interventional EUS, interventional radiology and oncology from 11 Asian countries (table 1). Between June 2014 and October 2016 the panellists met in meetings to discuss and vote on the clinical scenarios for each of the interventional EUS procedures in question. For each statement, the panellists were asked to score the appropriateness of the management in each scenario. Appropriateness was scored from 1 (highly inappropriate) to 9 (highly appropriate). The data were analysed for areas of agreement and disagreement. Agreement was met when $\leq 4$ panellists rated outside the 3 -point region containing the median (ie, 1-3, 4-6, 7-9). Disagreement occurred when $\geq 4$ panellists rated in each extreme 3-point region (ie, 1-3, 7-9). Discussions were focused on areas where there was disagreement. Statements were rewritten for clarification based on discussions and recommendations from the expert panel if there was disagreement. In statements where consensus could not be achieved, they were deleted from voting. All scenarios were re-voted for appropriateness by each panellist until agreement was obtained. In the final analysis, a procedure was classified as appropriate if the median rating was 7-9, with agreement; inappropriate if the median rating was $1-3$, with agreement; and uncertain if the median rating was $4-6$, with agreement. The level of agreement was indeterminate when it failed to satisfy either of these criteria. When there was agreement that the scenario was appropriate, it was then scored for necessity in the same manner. The final level of agreement reflects the median appropriateness scores and the dispersion of the scoring (reflected by the mean absolute deviations from the median). For pseudocyst drainage and pancreatic duct drainage, four rounds of revisions of the 
Table 1 Expert Panel members, specialty and hospital affiliation

\begin{tabular}{|c|c|c|c|}
\hline Name & Specialty & Affiliation & Location \\
\hline Anthony Yuen Bun, Teoh & Surgery & The Chinese University of Hong Kong & Hong Kong SAR, China \\
\hline Vinay, Dhir & Gastroenterology & Baldota Institute of Digestive Sciences & Mumbai, India \\
\hline Mitsuhiro, Kida & Gastroenterology Interventional radiology & Kitasato University East Hospital & Kitasato, Japan \\
\hline Ichiro, Yasuda & Gastroenterology & Teikyo University Mizonokuchi Hospital & Kawasaki, Japan \\
\hline Zhen Dong, Jin & Gastroenterology & Changhai Hospital & Shanghai, China \\
\hline Dong Wan, Seo & Gastroenterology & Asan Medical Centre & Seoul, Korea \\
\hline Majid, Almadi & Gastroenterology & King Khalid University Hospital, King Saud University & Riyadh, Saudi Arabia \\
\hline Kazuo, Hara & $\begin{array}{l}\text { Gastroenterology Interventional Radiology } \\
\text { Oncology }\end{array}$ & Aichi Cancer Centre Hospital & Nagoya, Japan \\
\hline Ida, Hilmi & Gastroenterology & University of Malaya & Kuala Lumper, Malaysia \\
\hline Takao, Itoi & Gastroenterology Interventional radiology & Tokyo Medical University & Tokyo, Japan \\
\hline Sundeep, Lakhtakia & Gastroenterology & Asian Institute of Gastroenterology & Hyderabad, India \\
\hline Tiing Leong, Ang & Gastroenterology & Changi General Hospital & Singapore \\
\hline Koji, Matsuda & Gastroenterology & St Marianna University School of Medicine & Kawasaki, Japan \\
\hline Nonthalee, Pausawasdi & Gastroenterology & Faculty of Medicine Siriraj Hospital, Mahidol University & Bangkok, Thailand \\
\hline Rajesh, Puri & Gastroenterology & $\begin{array}{l}\text { Institute of Digestive \& Hepatobiliary Sciences Medanta, } \\
\text { Medicity }\end{array}$ & Gurgaon, India \\
\hline Raymond Shing Yan, Tang & Gastroenterology & The Chinese University of Hong Kong, & Hong Kong SAR, China \\
\hline Hsiu-Po, Wang & Gastroenterology & National Taiwan University College of Medicine and Hospital & Taipei, Taiwan \\
\hline Dong, Wang & Gastroenterology & Changhai Hospital & Shanghai, China \\
\hline Ai-ming, Yang & Gastroenterology & Peking Union Medical College Hospital & Beijing, China \\
\hline Kenjiro, Yasuda & Gastroenterology & Kyoto Second Red Cross Hospital & Kyoto Japan. \\
\hline Khek Yu, Ho & Gastroenterology & National University of Singapore & Singapore. \\
\hline
\end{tabular}

statements were required to reach an agreement for each procedure; for celiac plexus ablations, five rounds of revisions were required; and biliary drainage required seven rounds of statement revisions. The statements of each of the interventional EUS procedures are presented here. For each of the statements, the evidence supporting them was graded according to the approach as suggested by the Grading of Recommendations, Assessment, Development and Evaluation (GRADE) Working Group. ${ }^{14}$ The quality of evidence was rated high when we were very confident that the true effect lies close to that of the estimate of the effect; it was rated moderate if we were moderately confident of the effect estimate; it was rated low if our confidence estimate was limited and very low if we had very little confidence in the effect estimate.

\section{RESULTS}

\section{Consensus statements on the optimal management of EUS- guided pancreatic pseudocyst drainage}

Consensus statements on the optimal management of EUS-guided pancreatic pseudocyst drainage are shown in table 2.

\section{Indications for the procedure}

\section{Statement 1}

Acute pseudocysts should be drained if they persist for more than 4-6 weeks, have a mature wall and are $\geq 6 \mathrm{~cm}$ in size, causing symptoms or complications.

Statement is Appropriate (9.0)

Evidence level: Moderate

\section{Supporting evidence and comments}

Acute pseudocysts can occur in $6.3-35.5 \%$ of patients with acute pancreatitis. ${ }^{15-19} 60 \%$ of acute pseudocysts that are $<6 \mathrm{~cm}$ would resolve spontaneously and do not need treatment. Those $\geq 6 \mathrm{~cm}$ are associated with a higher risk of developing complications and more frequently require interventions. ${ }^{2021}$ Time should be allowed for maturation of the cyst wall for drainage and this usually takes 4-6 weeks. Further delay in drainage beyond 8 weeks may increase the risk of developing complications. ${ }^{21}$ The presence of symptoms or an enlarging pseudocyst is correlated with the need for intervention. Complications from the pseudocyst can occur and include haemorrhage, infection, rupture, obstruction of the gastrointestinal tract and bile duct, and warrant intervention. ${ }^{22}$

\section{Optimal approach for drainage}

\section{Statement 2}

EUS-guided drainage is the optimal drainage approach in uncomplicated pseudocysts that are located adjacent to the stomach or duodenum.

Statement is Appropriate (9.0)

Evidence level: High

\section{Supporting evidence and comments}

Pancreatic pseudocysts can be drained by endoscopic, percutaneous and surgical approaches. ${ }^{10} 23-33$ Endoscopic approaches can be further divided into oesophagogastroduodenscopy (OGD)-guided or EUS-guided drainage. In a systematic review comparing the outcomes of various approaches, it was noted that surgical drainage appeared to reduce mortality and the adverse events rate compared with the percutaneous approach, while the EUS approach reduced hospital stay, cost and improved quality of life compared with surgery (table 3). EUS- and OGD-guided drainage were both feasible for pseudocyst drainage, but the success rate of the EUS approach was better for non-bulging cysts and the approach conferred additional safety benefits. The use of EUS improves the precision of drainage by allowing visualisation of extraluminal structures and intervening blood vessels. Results from two randomised trials and two retrospective studies 
Table 2 Consensus statements on the optimal management of endoscopic ultrasonography (EUS)-guided pancreatic pseudocyst drainage

Final level of Evidence

Indications for the procedure

agreement level

1 Acute pseudocysts should be drained if they persist for more than 4-6 weeks, have a mature wall and are $\geq 6 \mathrm{~cm}$ in size, causing symptoms or complications

Optimal approach for drainage

$2 \quad$ EUS-guided drainage is the optimal drainage approach in uncomplicated pseudocysts that are located adjacent to the stomach or duodenum

Pre-drainage evaluation

3 Pre-drainage evaluation includes CECT or MRCP and occasionally prior EUS to decide on the best approach for drainage

$4 \quad$ Multidisciplinary involvement including an endoscopist, interventional radiologist and surgeons is required in complicated cases to decide on the best approach to drainage

Pre-procedural preparations

$5 \quad$ Prophylactic antibiotics are recommended and should be continued post-procedurally

Procedural considerations

6 The use of fluoroscopy is recommended during EUS-guided pseudocyst drainage

7 One or two plastic pigtail stents should be inserted to maintain the patency of the cystogastrostomy after EUS-guided drainage

8 The use of metallic stents for pancreatic pseudocyst drainage outside a clinical trial is not recommended

$9 \quad$ The risk of pseudocyst recurrence may be increased in patients with pancreatic ductal disruption

Adjunctive treatments

10 The insertion of a pancreatic ductal stent is suggested in patients with partially disrupted pancreatic ducts

11 The use of nasocystic catheters is recommended in large or infected pseudocysts

Appropriate (9.0) Moderate

Management of complications

12 Centres performing the procedure should have multidisciplinary support including interventional radiologist, surgeons and anaesthesiologist to prevent and manage complications

Appropriate (9.0) High

Appropriate (9.0) Moderate

Appropriate (9.0) Low

Competency and training

13 Skills in EUS-guided pseudocyst drainage are best acquired through observation, followed by hands-on training in the porcine model Appropriate (7.0) Moderate and then performance of the procedure in patients

14 ERCP skills are beneficial to the endoscopist learning EUS-guided pseudocyst drainage and should be incorporated into the training Appropriate (9.0) Low programme

15 Performance of 5-10 supervised procedures is required to gain competency in EUS-guided pseudocyst drainage

Appropriate (7.0) Low

CECT, contrast-enhanced computed tomography; ERCP, endoscopic retrograde cholangiopancreatography; MRCP, magnetic resonance cholangiopancreatography.

are available. The studies employed EUS in different stages of the procedures. $^{27-29} 34$ The EUS-guided approach was associated with significantly higher success rates in two studies. ${ }^{27} 29$ Differences in adverse events were not significant, but clinically significant bleeding was reported in one study resulting in one death and another requiring endoscopic haemostasis and blood transfusion. $^{29}$

Thus, EUS-guided drainage appeared to be advantageous in drainage of pancreatic pseudocysts located adjacent to the stomach or duodenum. In patients with unfavourable anatomy,

Table 3 Studies comparing the outcomes of various approaches for pseudocyst drainage

\begin{tabular}{|c|c|c|c|c|c|c|c|c|}
\hline Authors & Sample size & $\begin{array}{l}\text { Clinical } \\
\text { success (\%) }\end{array}$ & Hospital stay (days) & Reintervention (\%) & Mortalities (\%) & Adverse events (\%) & Bleeding (\%) & $\begin{array}{l}\text { Intra-abdominal } \\
\text { infection (\%) }\end{array}$ \\
\hline \multirow[t]{2}{*}{ Varadarajulu $u^{24}$} & EUS: 20 & 95 & $2(1-4)^{*}+$ & 5 & 0 & 0 & 0 & 0 \\
\hline & Open: 20 & 100 & $6(5-9)^{*}$ & 5 & 0 & 2 & 1 & 0 \\
\hline \multirow[t]{3}{*}{ Melman ${ }^{25}$} & EUS: 45 & $51.1 \dagger$ & $3.9(0-25) \ddagger$ & - & 0 & 15.6 & 2.2 & 0 \\
\hline & Lap: 16 & 87.5 & $6.9(3-23) \ddagger$ & - & 0 & 25 & 12.5 & 0 \\
\hline & Open: 22 & 81.2 & $10.8(4-82) \ddagger$ & - & 0 & 22.7 & 0 & 0 \\
\hline \multirow[t]{2}{*}{ Varadarajulu ${ }^{26}$} & EUS: 20 & 95 & $2.6(1-11) \dagger \ddagger$ & 0 & 0 & 0 & 0 & 0 \\
\hline & Open: 10 & 100 & $6.5(4-20) \ddagger$ & 10 & 0 & 0 & 0 & 0 \\
\hline \multirow[t]{2}{*}{ Park $^{27}$} & EUS: 31 & 89 & - & 6.5 & 0 & 7 & 3.2 & - \\
\hline & EGD: 29 & 86 & - & 6.5 & 0 & 10 & 6.9 & - \\
\hline \multirow[t]{2}{*}{ Varadarajulu ${ }^{29}$} & EUS: 15 & $100 t$ & $2(1-9)^{*}$ & - & 0 & 0 & 0 & - \\
\hline & EGD: 15 & 33 & $1(1-8)^{*}$ & - & 6.7 & 13.3 & 13.3 & - \\
\hline \multirow[t]{2}{*}{ Kahaleh $^{34}$} & EUS: 46 & 84 & - & 10.9 & 0 & 19.6 & 4.3 & 8.7 \\
\hline & EGD: 53 & 91 & - & 9.4 & 0 & 18.9 & 1.9 & 7.5 \\
\hline
\end{tabular}

*Values are mean (IQR).

tIndicates significant differences between the two groups.

$\ddagger$ Values are mean (range) except otherwise indicated.

EGD, oesophagogastroduodenoscopy drainage; EUS, endoscopy ultrasonography drainage; Lap, laparoscopic drainage; Open, open drainage. 
surgical cystojejunostomy or percutaneous drainage could be considered. Similar findings were noted in another Cochrane review. $^{23}$

\section{Pre-drainage evaluation Statement 3}

Pre-drainage evaluation includes contrast-enhanced computed tomography (CECT) or magnetic resonance cholangiopancreatography (MRCP) and occasionally prior EUS to decide on the best approach for drainage.

Statement is Appropriate (9.0)

Evidence level: Moderate

\section{Supporting evidence and comments}

A pseudocyst usually develops posterior to the stomach, duodenum or towards the paracolic gutter. However, it can also form at atypical locations including the mediastinum, intrahepatic, intra/perisplenic, perirenal and pelvic areas. ${ }^{35-37}$ Hence, a CECT or MRCP is essential in delineating the anatomy. When available, MRI is preferred over CECT for depicting the presence of any solid debris within the pancreatic fluid collection. ${ }^{38}$ In addition, the use of EUS may sometimes be needed to assess the feasibility of endoscopic drainage and to assess the presence of intervening vessels.

\section{Statement 4}

Multidisciplinary involvement including an endoscopist, interventional radiologist and surgeons is required in complicated cases to decide on the best approach to drainage.

Statement is Appropriate (9.0)

Evidence level: Low

\section{Supporting evidence and comments}

EUS-guided drainage of pseudocysts offers high technical and clinical success rates. However, some situations may be challenging to the endoscopist and a multidisciplinary meeting would be useful to decide on the best approach for drainage. These include pseudocysts that are recurrent, at atypical locations, infected or bleeding. For pseudocysts that are not adjacent to the stomach or duodenum, surgical cystoenterostomy should be the subsequent choice of procedure. ${ }^{10}$ This could be done by laparoscopic or open means. Surgical resection may be indicated in patients with a bleeding pseudocyst or a recurrent pseudocyst due to disconnected duct syndrome. Laparoscopic cholecystectomy could be performed at the same operation. Percutaneous drainage may be indicated in ruptured pseudocysts or moribund patients who could not undergo endoscopic or surgical drainage.

\section{Pre-procedural preparations \\ Statement 5}

Prophylactic antibiotics are recommended and should be continued post-procedurally.

Statement is Appropriate (8.0)

Evidence level: Low

\section{Supporting evidence and comments}

There are no randomised controlled studies addressing the use of prophylactic antibiotics prior to pseudocyst drainage. There are also no data on whether antibiotics should be continued after the procedure and how long they should be continued. However, by draining the pseudocyst into the stomach, the endoscopist is converting a clean system to a clean-contaminated environment. Furthermore, given the low cost of antibiotics and infection being the most common complication after the procedure, provision of antibiotics before the procedure should be recommended. Available studies on the use of antibiotics mainly investigated their role in preventing infection of pancreatic necrosis and used different antibiotic regimes. ${ }^{39-45}$ These studies used high-dose second/third-generation cephalosporins or imipenem group antibiotics. A similar regime should be adopted as prophylactic antibiotics for pseudocyst drainage. Pseudocyst fluid should also be aspirated at the time of puncture to guide subsequent therapy if infection ensues. The Committee also agreed that antibiotics should be continued after the procedure, but the exact duration is uncertain. However, a period of 3-5 days after the procedure is common practice.

\section{Procedural considerations}

Statement 6

The use of fluoroscopy is recommended during EUS-guided pseudocyst drainage.

Statement is Appropriate (9.0)

Evidence level: Low

\section{Supporting evidence and comments}

EUS-guided pseudocyst drainage is a multi-step procedure involving puncturing of the cyst, track dilation and stent insertion. The use of fluoroscopy is essential for monitoring the position of the guidewire during looping within the pseudocyst and also stent placement. Although two studies have demonstrated the feasibility of performing the procedure under EUS guidance only, the Committee believes that the use of X-rays can provide another dimension of visual assessment during the procedure and improve safety without incurring additional risks. ${ }^{46} 47$

\section{Statement 7}

One or two plastic double pigtail stents should be inserted to maintain the patency of the cystogastrostomy after EUS-guided drainage.

Statement is Appropriate (8.0)

Evidence level: Moderate

\section{Supporting evidence and comments}

Until recently, plastic double pigtail stents were the standard stents used for pseudocyst drainage. These stents are cheap, safe and easily accessible. ${ }^{48}$ Technical and clinical success rates of over 90\% have been reported. ${ }^{2426} 29$ However, no randomised studies have addressed the optimal number of plastic stents that should be inserted. In a retrospective study, no difference in treatment success was found with respect to the size of stents ( 7 Fr vs $10 \mathrm{Fr}: 87.7 \%$ vs $90.5 \%$; $\mathrm{P}=0.766$ ) or the number of stents (1 vs >1 stent: $88.9 \%$ vs $88.6 \%$, $\mathrm{P}=0.999) .{ }^{49}$ On multiple logistic regression analysis, the stent size and number were also not predictors of the number of interventions required for treatment success. Thus, the endoscopist needs to exercise judgement on the likelihood of stent occlusion from cyst contents and decide if one or multiple stents is required.

\section{Statement 8}

The use of metallic stents for pancreatic pseudocyst drainage outside a clinical trial is not recommended.

Statement is Appropriate (7.0)

Evidence level: Moderate 


\section{Supporting evidence and comments}

The use of self-expanding metal stents (SEMS) for pseudocyst drainage is increasingly reported. ${ }^{50-62}$ Metal stents may offer several potential advantages to drainage of pseudocysts, including improved drainage with a larger diameter stent, reduced risk of stent obstruction, direct endoscopic access to the collection, reduced number of instrumental changes and possibly reduced procedural time. The types of SEMS can be divided into straight tubular stents or EUS-specific doubleflanged stents. The double-flanged stents can be further divided into lumen apposing (LAMS) and non-lumen apposing stents. ${ }^{63}$ EUS-specific stents possess design characteristics with EUS-guided deployment in mind. The stents are short, large diameter and bi-flanged to provide some anti-migratory properties. A further distinction on whether these stents are LAMS based on the strength of the lumen apposing force generated by the flanges was made. In theory, stents with a higher lumen apposing force can hold two non-adhering lumens together better and reduce the chance of leakage or stent migration. However, as described in a study below, such high lumen apposing force may also be a potential cause for adverse events. Hence, whether LAMS are more beneficial than non-LAMS is still controversial. Furthermore, there is no accepted definition on what properties LAMS should possess.

There are currently no randomised data on how metal stents compare with plastic stents for pseudocyst drainage. A distinction between the outcomes of SEMS for pseudocysts and walled-off pancreatic necrosis (WOPN) should also be made. In a systematic review, no differences in technical and clinical success were noted. ${ }^{48}$ Studies that used tubular SEMS reported an adverse events rate of $0-44.4 \% .^{50-54}$ The types of adverse events encountered included bleeding, infection and stent migration. On the other hand, the reported adverse events rates of doubleflanged stents in pancreatic pseudocysts ranged from $6.7 \%$ to $11.1 \% .^{55-61}$ In a recent report of an ongoing randomised trial assessing the role of LAMS for WOPN, serious adverse events including delayed bleeding, buried stent syndrome and biliary stricture were observed in up 50\% of the recruited patients. ${ }^{62}$ Hence, there is currently no place for the use of metal stents for pseudocyst drainage. In addition, any benefits arising from the use of SEMS will need to be balanced against the increased cost of the device, as a recent publication concluded that the use of LAMS is more expensive than plastic stents without significant differences in outcomes.

\section{Statement 9}

The risk of pseudocyst recurrence may be increased in patients with pancreatic ductal disruption.

Statement is Appropriate (9.0)

Evidence level: Moderate

\section{Supporting evidence and comments}

The development of pancreatic fluid collections is related to the disruption of the pancreatic duct with extravasation of pancreatic juice. The presence of main pancreatic duct disruptions was more often seen in patients with pancreatic necrosis and the finding was associated with a longer hospital stay. ${ }^{64} 65$ Pancreatic duct disruptions can be classified into complete or partial. A partial duct disruption is present when part of the duct wall is still in continuity and is signified when the main pancreatic duct is opacified upstream from the disruption site during endoscopic retrograde cholangiopancreatography (ERCP). Complete disruption is signified as an abrupt cut-off and/or extravasation of injected contrast medium without filling of the upstream pancreatic duct during ERCP. ${ }^{66}$

In one study, complete disruption was more frequently associated with $>50 \%$ necrosis and full-thickness glandular necrosis compared with partial disruption. ${ }^{66}$ The success rate of endoscopic transpapillary pancreatic stenting across the stricture site was also lower in complete disruption ( $20 \%$ vs $92 \%, \mathrm{P}=0.01)$. Patients with complete main pancreatic duct disruption also showed a higher rate of pancreatic fluid collection recurrence (71\% vs $17 \%, \mathrm{P}=0.003)$ and required surgery more often $(43 \%$ vs $6 \%, \mathrm{P}=0.027)$.

\section{Adjunctive treatments \\ Statement 10}

The insertion of a pancreatic ductal stent is suggested in patients with partially disrupted pancreatic ducts.

Statement is Appropriate (8.0)

Evidence level: Moderate

\section{Supporting evidence and comments}

The use of pancreatic duct stenting as a treatment for persistent pancreatic duct leak was reported in several studies. ${ }^{66-76}$ Most of the studies consisted of a small number of patients and the success rate in achieving permanent resolution of the leak was $50-88 \%$. A distinction between partial and complete pancreatic duct disruptions was made in five studies. ${ }^{66} 69-7173$ In two studies, a stent that bridged the disruption correlated with a successful outcome. ${ }^{69} 70$ The success rate of placing a pancreatic stent was significantly lower in patients with complete disruption compared with partial disruption $(20 \%$ vs $92 \%, \mathrm{P}=0.001) .{ }^{66}$

\section{Statement 11}

The use of nasocystic catheters is recommended in large or infected pseudocysts.

Statement is Appropriate (8.0)

Evidence level: High

\section{Supporting evidence and comments}

The use of a nasocystic catheter in conjunction with transmural stenting was reported in four studies, three in pseudocysts and one in walled off pancreatic necrosis. ${ }^{77-81}$ The nasocystic catheter is used to provide continuous irrigation and drainage of the cyst cavity in an aim to prevent or treat infection. The size of the catheter was 5-7 Fr. The volume of irrigation used was highly variable. One study used $50 \mathrm{~mL}$ of normal saline three times daily, another study irrigated $100 \mathrm{~mL} /$ hour of normal saline solution for 48-72 hours, and the volume was not specified in two studies. In the only randomised study that included pseudocysts of $10 \mathrm{~cm}$ or larger, the infection rates, hospital stay and resolution time of the pseudocyst were significantly lower with the use of nasocystic catheters. ${ }^{80}$ In the study on WOPN, the use of nasocystic catheters was associated with a lower risk of stent occlusion. Thus, the use of nasocystic catheters is suggested in large or infected pseudocysts.

\section{Management of complications \\ Statement 12}

Centres performing the procedure should have multidisciplinary support including interventional radiologist, surgeons and anaesthesiologist to prevent and manage complications.

Statement is Appropriate (9.0)

Evidence level: Low 


\section{Supporting evidence and comments}

EUS-guided pseudocyst drainage is a relatively safe procedure with a risk of adverse events ranging from $0 \%$ to $34 \% .{ }^{102}$ Most patients can be discharged within 1-2 days after the procedure. Nevertheless, severe life-threatening conditions can occur in patients who develop bleeding, infection or perforation. Bleeding can occur during creation of a transmural track or as a result of stent erosion. ${ }^{29} 616282$ The condition has been reported with the use of plastic stents and SEMS. Prompt treatment by interventional radiology with angiographic embolisation is often required..$^{83}$ Infection is usually due to an obstructed stent and requires endoscopic stent exchange. Perforation can occur when the transmural track is lost, and the condition is traditionally managed by surgery. However, recent advances in endoscopic accessories have allowed most perforations to be managed endoscopically by clipping or suturing. ${ }^{84} 85$ Thus, institutions performing the procedure should have facilities to manage these conditions.

\section{Competency and training \\ Statement 13}

Skills in EUS-guided pseudocyst drainage are best acquired through observation, followed by hands-on training in the porcine model and then performance of the procedure in patients.

Statement is Appropriate (7.0)

Evidence level: Moderate

\section{Supporting evidence and comments}

Data from the Asian EUS group workshops have shown that a dedicated training programme improves knowledge and skills in EUS. ${ }^{86}$ Observation of the procedure should best be in highvolume centres experienced in interventional EUS. Hands-on training should begin in the porcine model and trainees should familiarise themselves with the steps of the procedure and instruments that they are using. ${ }^{87}$ When proficiency is obtained in models, trainees should then perform the procedure under the supervision of an experienced endoscopist.

\section{Statement 14}

ERCP skills are beneficial to the endoscopist learning EUS-guided pseudocyst drainage and should be incorporated into the training programme.

Statement is Appropriate (9.0)

Evidence level: Low

\section{Supporting evidence and comments}

There is limited literature addressing this issue. However, since many of the instruments and techniques used in the procedure were borrowed from ERCP, the panel believes that proficiency in ERCP skills, although not essential, would be beneficial to endoscopists learning EUS-guided pseudocyst drainage. ${ }^{88}$

\section{Statement 15}

Performance of 5-10 supervised procedures is required to gain competency in EUS-guided pseudocyst drainage.

Statement is Appropriate (7.0)

Evidence level: Low

\section{Supporting evidence and comments}

The literature is also scarce in addressing this issue. Two studies have examined the impact on outcomes with increasing experience of the procedure. ${ }^{89} 90$ In one study it was observed that resolution rates and days to resolution were significantly improved after the first 20 procedures ${ }^{89}$ while, in another study, the procedural time was found to be significantly shorter after the first 25 procedures without differences in technical success, clinical success and adverse events rates. ${ }^{90}$ However, the Committee acknowledges that both of these studies were reported during the early development of the technique. The technique was still in evolution and endoscopists were performing the procedure without supervision. Hence, using current standards of performing the procedure and assuming that the endoscopist is competent in ERCP, a lower number of procedures would be required to attain competency. It was thus agreed that performance of $5-10$ procedures under supervision is the minimum requirement to obtain competency. However, the learning curve of each trainee is different and each should be assessed individually to assess for their competency.

\section{Consensus statements on the optimal management of EUS- guided biliary drainage (EUS-BD)}

Consensus statements on the optimal management of EUS-guided biliary drainage (EUS-BD) are shown in table 4 .

\section{Indications for the procedure}

\section{Statement 1}

EUS-BD is recommended as the procedure of choice for biliary drainage in patients with failed ERCP if expertise is available.

Statement is Appropriate (8.0)

Evidence level: High

\section{Supporting evidence and comments}

EUS-BD has emerged as an acceptable alternative in patients with obstructive jaundice and failed ERCP (table 5). ${ }^{91}$ Two meta-analyses have demonstrated EUS-BD to have high technical success in excess of $90 \%$ with adverse event rates in the range of $17-23 \% .{ }^{92} 93$ A randomised study has shown EUS-BD to be superior to percutaneous transhepatic biliary drainage (PTBD) in expert hands in terms of adverse events and re-intervention rate. ${ }^{94}$ Procedure-related adverse events were $8.8 \%$ in the EUS-BD group compared with $31.2 \%$ in the PTBD group ( $\mathrm{P}=0.022)$, while the mean frequency of unscheduled re-intervention was 0.34 in the EUS-BD group and 0.93 in the PTBD group $(\mathrm{P}=0.02)$. EUS-BD (choledochoduodenostomy) has also been compared with surgical hepaticojejunostomy in a small randomised trial. ${ }^{95}$ Technical and clinical success was comparable between the two groups. However, the procedural time of EUS-BD was significantly shorter $(\mathrm{P}=0.027)$, while no difference was observed in adverse events rates $(\mathrm{P}=0.651)$ and quality of life scores.

\section{Statement 2}

EUS-BD is an alternative procedure to obtain biliary drainage in patients with altered postoperative anatomy or duodenal stenosis precluding ERCP if expertise is available.

Statement is Appropriate (8.0)

Evidence level: Moderate

\section{Supporting evidence and comments}

Approaching the papilla may be difficult or impossible in patients with duodenal stenosis or surgically altered anatomy with endoscopy. The success rate of ERCP in these situations is dependent on reaching the papilla, which may not be possible in up to $40 \%$ of patients. ${ }^{96}$ EUS-BD is a good alternative in such situations as the bile duct can be accessed from the proximal stomach. Available literature shows a high success rate of 


\section{Table 4 Consensus statements on the optimal management of endoscopic ultrasonography-guided biliary drainage (EUS-BD)}

\begin{tabular}{|c|c|c|c|}
\hline & Statements & $\begin{array}{l}\text { Final level of } \\
\text { agreement }\end{array}$ & $\begin{array}{l}\text { Evidence } \\
\text { level }\end{array}$ \\
\hline & \multicolumn{3}{|l|}{ Indications for the procedure } \\
\hline 1 & EUS-BD is recommended as the procedure of choice for biliary drainage in patients with failed ERCP if expertise is available & Appropriate (8.0) & High \\
\hline 2 & \multicolumn{3}{|l|}{ Optimal approach for drainage } \\
\hline 3 & In patients with distal common bile duct obstruction, the transduodenal and transhepatic approaches for EUS-BD are used & Appropriate (8.0) & Moderate \\
\hline 4 & \multicolumn{3}{|l|}{ Pre-drainage evaluation } \\
\hline \multirow[t]{2}{*}{5} & MRCP or CECT is recommended in patients with suspected hilar obstruction prior to the EUS-BD procedure & Appropriate (9.0) & Very Low \\
\hline & \multicolumn{3}{|l|}{ Pre-procedural preparations } \\
\hline \multirow[t]{2}{*}{6} & Antibiotic prophylaxis is recommended before the EUS-BD procedure & Appropriate (9.0) & Moderate \\
\hline & \multicolumn{3}{|l|}{ Procedural considerations } \\
\hline \multirow[t]{2}{*}{11} & The use of metal stents is recommended over plastic stents for EUS-BD to reduce the risk of bile leak & Appropriate (8.0)) & Low \\
\hline & \multicolumn{3}{|l|}{ Management of complications } \\
\hline \multirow[t]{2}{*}{12} & $\begin{array}{l}\text { Multidisciplinary support including interventional radiologist, surgeons and anaesthesiologist to prevent and manage complications } \\
\text { is recommended in centres performing EUS-BD }\end{array}$ & Appropriate (9.0) & Very Low \\
\hline & \multicolumn{3}{|l|}{ Competency and training } \\
\hline 13 & Training of EUS-BD should be done at expert centres with facilities and expertise in EUS, ERCP and PTBD. & Appropriate $(9.0)$ & Very Low \\
\hline 14 & $\begin{array}{l}\text { Training in EUS-BD should only commence in those endoscopists experienced in EUS-FNA, wire manipulation techniques and biliary } \\
\text { stent placement }\end{array}$ & Appropriate (9.0) & Low \\
\hline 15 & $\begin{array}{l}\text { Pig or ex vivo models are suitable for hands-on training on EUS-BD and should be incorporated into the training programme for } \\
\text { EUS-BD }\end{array}$ & Appropriate (8.0) & Low \\
\hline
\end{tabular}

CECT, contrast-enhanced computed tomography; ERCP, endoscopic retrograde cholangiopancreatography; FNA, fine needle aspiration; MRCP, magnetic resonance cholangiopancreatography; PTBD, percutaneous transhepatic biliary drainage.

EUS-BD in patients with altered anatomy. However, prospective comparative studies with ERCP are lacking. A retrospective study comparing the approaches showed that EUS-BD was associated with better success rates, reduced procedural times but higher adverse events rates. ${ }^{97}$

\section{Optimal approach for drainage}

\section{Statement 3}

In patients with distal common bile duct obstruction, the transduodenal and transhepatic approaches for EUS-BD are used.

Statement is Appropriate (8.0)

Evidence level: Moderate

\section{Supporting evidence and comments}

A number of EUS-BD procedures are available. The same procedure may be named differently depending on the literature and a standardised nomenclature was not available. ${ }^{98} 99$ The Asian EUS group has recently suggested a nomenclature for EUS-guided biliary interventions (figure 2). The procedures include access procedures (rendezvous technique) and direct drainage procedures. Prior to EUS-BD, the endoscopist should have an algorithm on whether EUS-BD is used for access or drainage, or both. When performing EUS-guided rendezvous ERCP, EUS is only used in the initial part of the procedure for bile duct access and introduction of a guidewire through the papilla. The echoendoscope is then changed to a duodenoscope for retrieval of the guidewire to complete the procedure with ERCP.

In terms of access, the bile duct can be accessed by the transduodenal and transhepatic routes. Both approaches have been found to be effective provided that the ducts are adequately dilated. There is lack of clarity about the preferred route when both routes are feasible for puncture. Current data are

Table 5 Randomised studies comparing EUS-guided biliary drainage (EUS-BD) versus percutaneous transhepatic biliary drainage and surgical bypass

\begin{tabular}{|c|c|c|c|c|c|c|c|c|}
\hline \multirow{2}{*}{$\begin{array}{l}\text { Author } \\
\text { Artifon }^{91}\end{array}$} & \multirow{2}{*}{$\begin{array}{c}\text { Year } \\
2012\end{array}$} & \multirow{2}{*}{$\begin{array}{l}\text { Patients } \\
\text { EUS: } 13\end{array}$} & \multirow{2}{*}{$\begin{array}{l}\text { Technical success (\%) } \\
100\end{array}$} & \multirow{2}{*}{$\begin{array}{l}\text { Clinical success (\%) } \\
100\end{array}$} & \multicolumn{2}{|c|}{ Adverse events (\%) } & \multicolumn{2}{|c|}{ Re-interventions (\%) } \\
\hline & & & & & 15.3 & $P=N S$ & - & \\
\hline & & PTBD: 12 & 100 & 100 & 25 & & & \\
\hline \multirow[t]{2}{*}{$\operatorname{Lee}^{94}$} & 2015 & EUS: 34 & 94.1 & 87.5 & 8.8 & $P=0.022$ & 25 & $P=0.022$ \\
\hline & & PTBD: 32 & 96.9 & 87.1 & 31.2 & & 54.8 & \\
\hline \multirow[t]{2}{*}{ Artifon $^{95}$} & 2015 & EUS: 14 & 88 & 71 & 21.42 & $P=0.651$ & - & \\
\hline & & Surgical HJ: 15 & 94 & 93 & 13.3 & & & \\
\hline
\end{tabular}

EUS, endoscopic ultrasonography drainage; HJ, hepaticojejunostomy; PTBD, percutaneous transhepatic biliary drainage. 


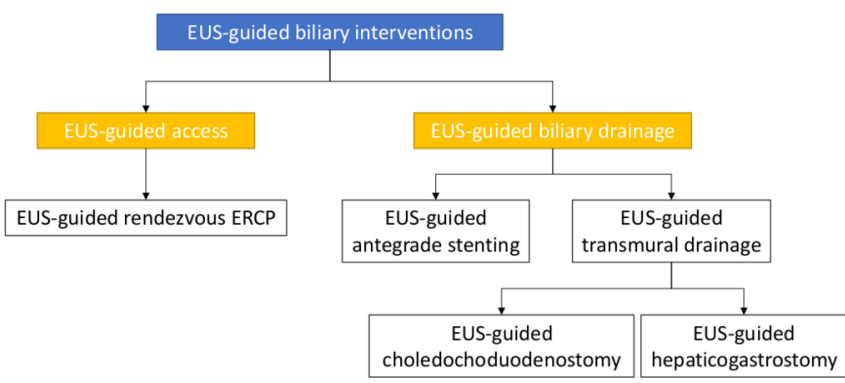

Figure 2 Nomenclature for endoscopic ultrasonography (EUS)-guided biliary interventions.

conflicting, with some reports showing the transduodenal route to be safer while others show no difference. ${ }^{97} 100$

Direct drainage procedures can be transpapillary (antegrade stenting) or transluminal (choledochoduodenostomy (CDS) and hepaticogastrostomy (HGS)). For CDS, a fistula track is first created between the common bile duct and the first part of the duodenum for insertion of a stent. For HGS, a fistula is first created between the left intrahepatic duct and the stomach followed by insertion of a stent. There are also reports of stents placed between the right intrahepatic duct and duodenum, but the procedure is more technically demanding. ${ }^{101}$ In a small randomised study comparing 25 patients who received HGS and 24 who received CDS, the clinical success of HGS was higher (91\% vs $77 \%)$ and the adverse events were also slightly higher ( $20 \%$ vs $12.5 \%$ ), although neither outcome reached statistical significance. ${ }^{102}$

Thus, in patients with distal common bile duct obstruction, both procedures could be performed. The choice of the procedure is not clear, but depends on a combination of factors including technical expertise, stent patency, risk of adverse events and anatomical factors including presence of dilated bile duct or biliary radicals, duodenal stenosis and altered anatomy.

\section{Statement 4}

A transhepatic approach to EUS-BD is recommended for hilar blocks.

Statement is Appropriate (8.0)

Evidence level: Low

\section{Supporting evidence and comments}

Transduodenal stent placement in a patient with hilar obstruction is likely to be more challenging than transhepatic stent placement. The transhepatic approach is preferred, and drainage could be obtained with antegrade stenting or HGS. The risk of cholangitis increases when contrast is injected into undrained ducts and care should be taken to avoid excessive contrast injection. 103104

\section{Pre-drainage evaluation}

Statement 5

MRCP or CECT is recommended in patients with suspected hilar obstruction prior to the EUS-BD procedure.

Statement is Appropriate (9.0)

Evidence level: Very Low

\section{Supporting evidence and comments}

MRCP provides a roadmap for stent placement by delineation of the type of hilar obstruction and other relevant bile duct anatomy. Inadvertent contrast injection and/or manipulation in a non-dilated or non-drainable segment could result in cholangitis. Thus, it is considered prudent to obtain MRCP prior to intervention in patients with hilar obstruction. There are no data regarding the utility of a roadmap in EUS-BD, but it appears logical based on data available for ERCP. ${ }^{105}$ In patients with distal common bile duct obstruction, an ultrasound or CECT could be performed as initial investigations prior to EUS-BD.

\section{Pre-procedural preparations}

\section{Statement 6}

Antibiotic prophylaxis is recommended before the EUS-BD procedure.

Statement is Appropriate (9.0)

Evidence level: Moderate

\section{Supporting evidence and comments}

There are no studies demonstrating the efficacy of prophylactic antibiotics in patients undergoing EUS-BD. However, the procedure is similar to other biliary interventions like ERCP and PTBD with contrast injection and manipulation done in an obstructed biliary system, resulting in introducing and/or disseminating bacteria. The use of antibiotics was shown to prevent cholangitis, septicaemia, bacteraemia and pancreatitis in ERCP, particularly for obstructed systems. ${ }^{106}$ Thus, prophylactic antibiotics should be used in a similar manner. Antibiotics that cover biliary flora such as enteric gram-negative organisms and enterococci should be used (second-generation cephalosporin or quinolone).

\section{Procedural considerations}

\section{Statement 7}

A 19-gauge EUS-FNA needle is recommended for duct puncture.

Statement is Appropriate (8.0)

Evidence level: Moderate

\section{Supporting evidence and comments}

A 19-gauge fine needle aspiration (FNA) needle allows passage of a 0.035 inch or 0.025 inch guidewire. Smaller size needles can be used but thinner wires will be required $(0.018$ inch or 0.021 inch). A 19 -gauge needle allows efficient wire manipulations, but may be difficult to manoeuvre in angulated positions like the duodenum. The use of 'flexible' nitinol needles may improve the manoeuvrability in such positions. ${ }^{107}$

\section{Statement 8}

A 0.035 inch or 0.025 inch guidewire with floppy tip should be used to negotiate the bile duct.

Statement is Appropriate (9.0)

Evidence level: Low

\section{Supporting evidence and comments}

Both types of wires appear to be equally effective for EUS-BD and they are the most common types of wires used for EUS-BD. The use of thinner wires is possible, but the wires are easy to kink and are not stable for tract dilation and stenting and should be used with caution. A $450 \mathrm{~cm}$ wire is commonly used, although some studies have used a shorter $240 \mathrm{~cm}$ glide wire to allow faster exchange of accessories. ${ }^{108}$

\section{Statement 9}

Catheters, balloons or cystotomes are recommended for tract dilation. Tract dilation with a precut papillotome is not recommended. 
Statement is Appropriate (8.0)

Evidence level: Low

\section{Supporting evidence and comments}

There are some data suggesting a higher complication rate when a precut papillotome is used for dilation. ${ }^{109} \mathrm{~A} 6$ Fr cystotome is favoured as it is fast and efficient. $5 \mathrm{Fr}$ stiff catheters and $4 \mathrm{~mm}$ biliary dilating balloons may be used if a cystotome is not available in some countries. Recently, one-step systems have become available and obviate the need for dilation as the cautery at the tip of the delivery catheter works as a dilator or cautery. ${ }^{110-112}$ These novel one-step systems avoid the need for repeated instrumental changes and reduced procedural times.

\section{Statement 10}

Fully or partially covered metal stents are recommended for transluminal stenting. Uncovered metal stents can be used for antegrade transpapillary stenting.

Statement is Appropriate (8.0)

Evidence level: Low

\section{Supporting evidence and comments}

Covered stents are preferred for transluminal procedures to prevent bile leak. Uncovered stents may be used for transpapillary procedures. LAMS are short dumbbell-shaped fully covered metallic stents with wide flanges to allow anchoring. ${ }^{63}$ There are limited data available for the use of LAMS except in EUS-guided CDS. ${ }^{111}$

\section{Statement 11}

The use of metal stents is recommended over plastic stents for EUS-BD to reduce the risk of bile leak.

Statement is Appropriate (8.0)

Evidence level: Low

\section{Supporting evidence and comments}

There are some data to suggest that bile leak is more common following plastic stent placement. In a large retrospective study, adverse events were significantly higher with plastic stents $(42.8 \%$ vs $13 \%, \mathrm{P}=0.01)$. In another study the incidence of cholangitis was significantly higher in the plastic stent group $(11 \%$ vs $3 \%, \mathrm{P}=0.02){ }^{100113}$

\section{Management of complications}

Statement 12

Multidisciplinary support including interventional radiologist, surgeons and anaesthesiologist to prevent and manage complications is recommended in centres performing EUS-BD.

Statement is Appropriate (9.0)

Evidence level: Very Low

\section{Supporting evidence and comments}

EUS-BD may give rise to severe adverse events like perforations, bile leaks and bleeding. ${ }^{114}$ It is advisable that surgical and interventional radiology support be available in centres performing EUS-BD.

\section{Competency and training}

Statement 13

Training of EUS-BD should be done at expert centres with facilities and expertise in EUS, ERCP and PTBD.

Statement is Appropriate (9.0)
Evidence level: Very Low

\section{Supporting evidence and comments}

EUS-BD is an advanced endoscopic technique that shares similar skills and accessories with ERCP and PTBD. Currently, EUS-BD is being used as a salvage procedure after failed ERCP. Facilities for PTBD should be available in the event of failed EUS-BD. The three procedures complement each other and training centres should have expertise in all these procedures.

\section{Statement 14}

Training in EUS-BD should only commence in those endoscopists experienced in EUS-FNA, wire manipulation techniques and biliary stent placement.

Statement is Appropriate (9.0)

Evidence level: Low

\section{Supporting evidence and comments}

There are no formal training programmes for EUS-BD at most centres. The number of patients undergoing EUS-BD is small even at advanced centres. There are no data on the experience an endoscopist is required to attain before training in EUS-BD should be commenced. However, it appears logical to impart training to candidates who are well versed with components of the EUS-BD procedure including FNA, wire manipulation and biliary stent placement.

\section{Statement 15}

Pig or ex vivo models are suitable for hands-on training on EUS-BD and should be incorporated into the training programme for EUS-BD.

Statement is Appropriate (8.0)

Evidence level: Low

\section{Supporting evidence and comments}

Pig models can be created by endoscopic ligation of the ampulla of Vater, resulting in dilation of the biliary system. ${ }^{115}$ The process is cumbersome and unpredictable in terms of the degree of biliary dilation obtainable. Ex vivo pig models are easier to create and may be suitable for training of biliary and gallbladder drainage. Three-dimensional (3D) printed models have been described. They appear to be useful but need more modifications. Finding the appropriate material for $3 \mathrm{D}$ printing is challenging. ${ }^{116}$

\section{Consensus statements on the optimal management of EUS- guided pancreatic duct drainage}

Consensus statements on the optimal management of EUS-guided pancreatic duct (EUS-PD) drainage are shown in table 6.

Indications for the procedure

\section{Statement 1}

EUS-PD is recommended in patients with pancreatic duct obstruction after failed ERCP.

Statement is Appropriate (8.0)

Evidence level: Moderate

\section{Statement 2}

EUS-PD is recommended in patients with pancreatic duct obstruction and surgically altered anatomy or duodenal stenosis where ERCP is not possible.

Statement is Appropriate (9.0)

Evidence level: Moderate 
Table 6 Consensus statements on the optimal management of endoscopic ultrasonography-guided pancreatic duct (EUS-PD) drainage

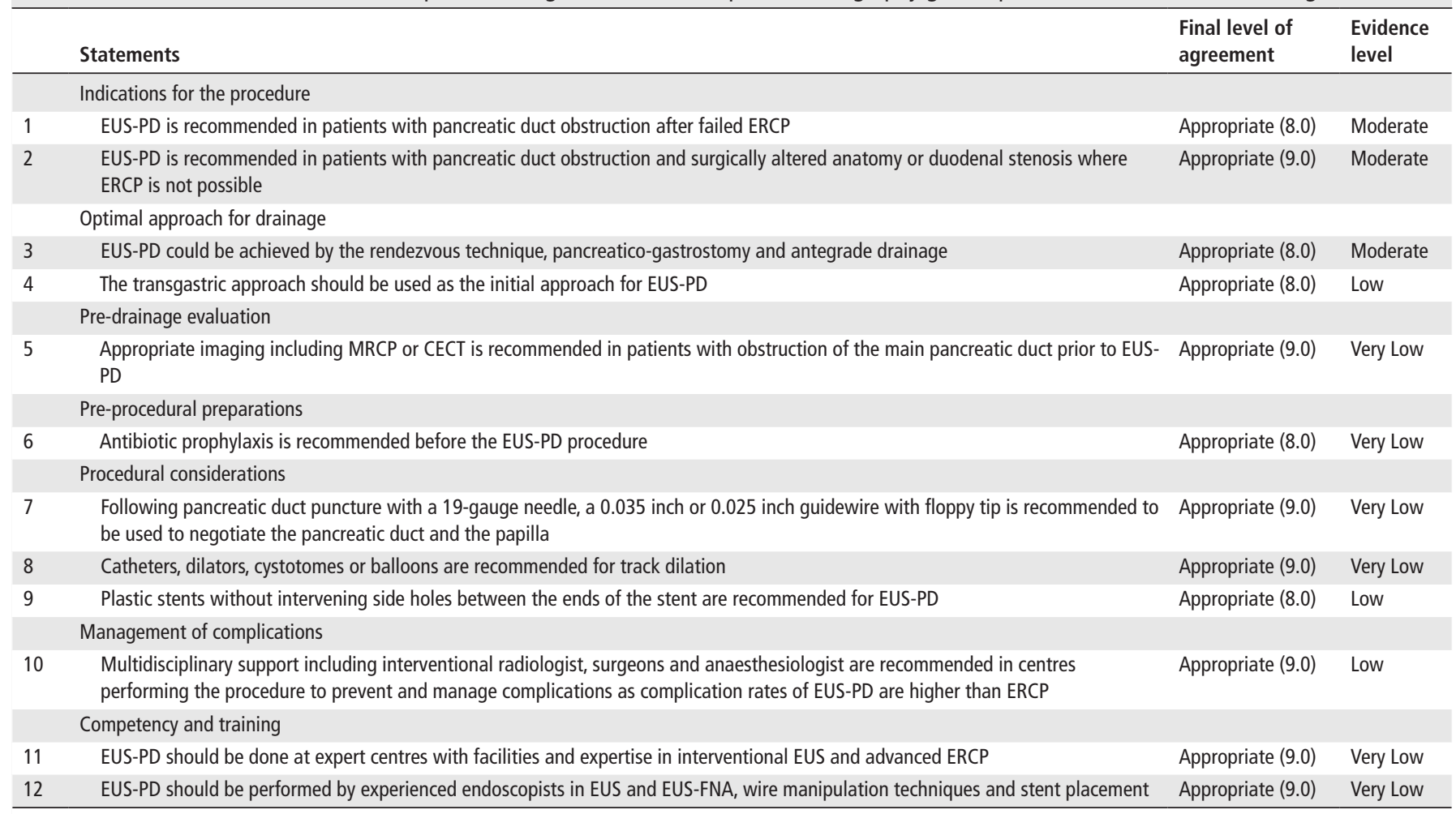

CECT, contrast-enhanced computed tomography; ERCP, endoscopic retrograde cholangiopancreatography; FNA, fine needle aspiration; MRCP, magnetic resonance cholangiopancreatography.

\section{Supporting evidence and comments (statements 1 and 2)}

While EUS and percutaneous approaches are alternatives to surgical biliary drainage after failed ERCP, EUS-PD is the only option for non-surgical pancreatic duct drainage after failed endoscopic retrograde pancreatography (ERP). ${ }^{11} 117118$ Outcomes in over 200 patients who received EUS-PD showed a pooled technical success rate of $76.6 \%$ and adverse events of $18.9 \% .{ }^{118}$ In patients where the papilla can be reached by the duodenoscope, pancreatic duct drainage should be attempted by ERP first. In patients with surgically altered anatomy, ERP with balloon enteroscopy could be performed. In patients with altered anatomy, however, the success rate of reaching the blind end of the roux limb is dependent on the length of the roux limb and ranges between 33\% and 88\%. ${ }^{119} 120$ Thus, the EUS approach provides an important alternative in these patients. In a recent study comparing EUS-PD with enteroscopy-assisted ERP, EUS-PD was associated with significantly higher technical and clinical success rates $(92.5 \%$ vs $20 \%, \mathrm{P}<0.001 \%$; and $87.5 \%$ vs $23.5 \%, \mathrm{P}<0.001$, respectively). ${ }^{121}$ However, there were also significantly more mild to moderate adverse events in the EUS-PD group ( $35 \%$ vs $2.9 \%, \mathrm{P}<0.001$ ) without significant differences in procedural times and hospital stay.

On the other hand, it was also noted that newer short-type single or double balloon enteroscopes have become available. ${ }^{122} 123$ Results from two large-scale studies showed that the success rate in reaching the blind end of the duodenum was $92.6-97 \%$ and the treatment success was $81.8-100 \%$, while adverse event rates were $5 \%$ in both studies. Thus, the success in reaching the blind end of the roux limb was significantly increased with the newer enteroscopes and studies comparing the outcomes of the EUS approach with the newer devices would be required to assess the advantages and disadvantages of both procedures.
Optimal approach for drainage

\section{Statement 3}

EUS-PD could be achieved by the rendezvous technique, pancreatico-gastrostomy and antegrade stenting.

Statement is Appropriate (8.0)

Evidence level: Moderate

\section{Supporting evidence and comments}

Similar to EUS-BD, EUS-PD could be divided into access procedure (rendezvous technique) and direct drainage procedures. ${ }^{11} 117$ 124-128 Direct drainage procedures can be transpapillary (antegrade stenting) or transluminal (pancreaticogastrostomy or pancreaticoduodenostomy). For the rendezvous technique, EUS is employed in the initial part of the procedure for pancreatic duct access and guidewire introduction. ERCP is then performed for guidewire retrieval and completion of the procedure. For the transluminal technique, a fistula is first created between the stomach or the duodenum with the pancreatic duct followed by stent insertion. In antegrade stenting, a guidewire is passed across the papilla after pancreatic duct puncture. The tract is then dilated for insertion of a stent across the papilla from the stomach.

\section{Statement 4}

The transgastric approach should be used as the initial approach for EUS-PD.

Statement is Appropriate (8.0)

Evidence level: Low

\section{Supporting evidence and comments}

The pancreatic duct could be punctured from several routes including the transgastric, transduodenal or transjejunal approach 
in surgically altered patients. The most common approach is the transgastric approach, followed by transduodenal or transjejunal. ${ }^{118} 129$ There are no data to suggest which approach is superior; however, the transgastric approach provides the endoscopist with the greatest flexibility on which part of the pancreas to puncture. The site of puncture also affects the direction the guidewire passes, which in turn affects stent placement.

\section{Statement 5}

Appropriate imaging including MRCP or CECT is recommended in patients with obstruction of the main pancreatic duct prior to EUS-PD.

Statement is Appropriate (9.0)

Evidence level: Very low

\section{Supporting evidence and comments}

Pre-procedural planning is an important element to successful pancreatic duct drainage by the EUS approach. In order to understand the anatomy in each patient, MRCP or CECT should be performed prior to the procedure. The optimal approach is selected by choosing the location with the shortest distance between the bowel lumen and the pancreatic duct, an absence of interposed vasculature, and maximal stability with an angle to allow tract dilation and device deployment. Since the point where ductal puncture is most convenient may not necessarily be the best to facilitate subsequent guidewire insertion and stent placement, pre-procedural imaging and planning is important to the success of the procedure.

\section{Pre-procedural preparations}

Statement 6

Antibiotic prophylaxis is recommended before the EUS-PD procedure.

Statement is Appropriate (8.0)

Evidence level: Very Low

\section{Supporting evidence and comments}

There are no studies demonstrating the efficacy of prophylactic antibiotics in patients undergoing EUS-PD. However, EUS-PD is similar to other endoscopic pancreaticobiliary interventions and may result in introduction and/or dissemination of bacteria. Thus, prophylactic antibiotics should be used in a similar manner. Antibiotics that cover biliary flora such as enteric gram-negative organisms and enterococci should be used (second-generation cephalosporin or quinolone).

\section{Procedural considerations}

\section{Statement 7}

Following pancreatic duct puncture with a 19-gauge needle, a 0.035 inch or 0.025 inch guidewire with floppy tip is recommended to be used to negotiate the pancreatic duct and the papilla.

Statement is Appropriate (9.0)

Evidence level: Very low

\section{Supporting evidence and comments}

A 19-gauge needle is frequently used to puncture the pancreatic duct. ${ }^{11117118128129}$ After puncture, a guidewire is inserted through the 19-gauge needle and to enter the pancreatic duct. The guidewire used should have enough stability for subsequent insertion of dilator and stent. The use of 0.035 inch and 0.025 inch guidewires with a hydrophilic tip may reduce the risk of kinking and buckling when negotiating tight strictures or stenosis. When the pancreatic duct can only be punctured with a 22-gauge needle, then a 0.018 inch or 0.021 inch guidewire is required. These wires kink easily and are not stable for tract dilation and stenting, so they should be used with caution.

\section{Statement 8}

Catheters, dilators, cystotomes or balloons are recommended for track dilation.

Statement is Appropriate (9.0)

Evidence level: Very Low

\section{Supporting evidence and comments}

Dilation of the needle tract is required prior to stent insertion. ${ }^{11} 117118128129$ The size of dilation depends on the diameter of the stent. The needle tract can be dilated with catheters and balloons used in ERCP. However, insertion of these instruments may be impossible in a calcified pancreas or when an acute angulation exists between the needle tract and the pancreatic duct. In this situation, electrocautery may be used to dilate the tract. However, the use of cautery can sometimes lead to pancreatitis, pancreatic leak, bleeding or perforation. Therefore, it is important to use cautery sparingly and adjust the direction of the electrocautery to the axis of the tract. ${ }^{117118129}$ The use of coaxial electrocautery may be preferable to a precut papillotome as the direction of cutting is along the axis of the tract, but no studies have compared the devices in EUS-PD.

\section{Statement 9}

Plastic stents without intervening side holes between the ends of the stent are recommended for EUS-PD.

Statement is Appropriate (8.0)

Evidence level: Low

\section{Supporting evidence and comments}

7 Fr straight plastic stents without intervening side holes between the ends of the stent are most commonly used, although stents of other sizes could also be employed. ${ }^{129} 130$ Straight stents may have more pushability than pigtail stents. However, stent migration was shown to occur more frequently compared with double pigtail plastic stents in one study (9\% vs $23 \%, \mathrm{P}=0.62) .{ }^{131}$ Recently, fully covered SEMS with antimigratory properties for EUS-PD have been reported. A technical and clinical success rate of $100 \%$ has been reported in 25 patients with significant reduction in pain scores after placement. ${ }^{132}$ However, the longterm outcomes of metal stents for EUS-PD will need further evaluation.

\section{Management of complications \\ Statement 10}

Multidisciplinary support including interventional radiologist, surgeons and anaesthesiologist are recommended in centres performing the procedure to prevent and manage complications as complication rates of EUS-PD are higher than ERCP.

Statement is Appropriate (9.0)

Evidence level: Low

\section{Supporting evidence and comments}

EUS-PD is a technically demanding procedure. A pooled technical success rate among 222 patients was $76.6 \%$ and adverse events rates were $18.9 \%$. Adverse events included pancreatitis, perforation, bleeding, peripancreatic pseudocyst/abscess formation, abdominal pain, pneumoperitoneum, pseudoaneurysm and shearing of guidewire coating. ${ }^{118} 133$ Prompt management of 
these adverse events is best done in a multidisciplinary manner. Furthermore, centres should be equipped with options to drain the pancreatic duct with advanced ERCP techniques or surgery in the event of failed EUS-PD.

\section{Competency and training}

Statement 11

EUS-PD should be done at expert centres with facilities and expertise in interventional EUS and advanced ERCP.

Statement is Appropriate (9.0)

Evidence level: Very Low

\section{Supporting evidence and comments}

As mentioned above, EUS-PD is a technically demanding procedure with a low margin for error even when performed in expert centres. Although not supported by any study, the group believes that centres performing EUS-PD should have abundant experience in interventional EUS and advanced ERCP in order to manage failures and adverse events promptly.

\section{Statement 12}

EUS-PD should be performed by experienced endoscopists in EUS and EUS-FNA, wire manipulation techniques and stent placement.

Statement is Appropriate (9.0)

Evidence level: Very Low

\section{Supporting evidence and comments}

The group believes that EUS-PD is one of the most difficult types of EUS drainage procedures. Endoscopists performing the procedure should have abundant experience in advanced EUS techniques and stent placement. In addition, abundant experience in other EUS-guided drainage procedures may improve the success rate and reduce the risk of adverse events.

\section{Consensus statements on the optimal management of EUS- guided celiac plexus ablation (neurolysis and gangliolysis)}

Consensus statements on the optimal management of EUS-guided celiac plexus ablation (neurolysis and gangliolysis) (EUS-CPN and $-\mathrm{CGN}$ ) are shown in table 7.

Indications for the procedure

\section{Statement 1}

EUS-guided celiac plexus neurolysis (CPN) is recommended in patients suffering from pain due to unresectable upper abdominal cancer, particularly for pancreatic cancer.

Statement is Appropriate (8.0)

Evidence level: High

\section{Supporting evidence and comments}

The celiac plexus is responsible for transmitting pain sensation originating from the upper abdominal organs including the pancreas, liver, gallbladder, stomach and ascending and transverse colons. CPN disrupts the transmission of pain signals from afferent nerves to the spinal cord by injecting a neurolytic agent into the celiac plexus. Therefore, EUS-CPN can be used for the treatment of pain arising from the upper abdominal cancers. Among them, pancreatic cancer is the most common indication as more than $80 \%$ of patients in the advanced stages

Table 7 Consensus statements on the optimal management of endoscopic ultrasonography-guided celiac plexus ablation (neurolysis and gangliolysis) (EUS-CPN and -CGN)

\begin{tabular}{|c|c|c|c|}
\hline & Statements & $\begin{array}{l}\text { Final level of } \\
\text { agreement }\end{array}$ & $\begin{array}{l}\text { Evidence } \\
\text { level }\end{array}$ \\
\hline & Indications for the procedure & & \\
\hline 1 & $\begin{array}{l}\text { EUS-guided CPN is recommended in patients suffering from pain due to unresectable upper abdominal cancer, particularly for } \\
\text { pancreatic cancer }\end{array}$ & Appropriate (8.0) & High \\
\hline \multirow[t]{2}{*}{2} & EUS-guided CPN for treatment of pain arising from chronic pancreatitis is not recommended & Appropriate (7.0) & Moderate \\
\hline & Optimal approach for drainage & & \\
\hline 3 & The EUS-guided approach is recommended over percutaneous image-guided techniques for celiac plexus ablation & Appropriate (9.0) & Moderate \\
\hline \multirow[t]{2}{*}{4} & Prophylactic antibiotics are suggested to be given when bupivacaine with steroids is used for EUS-CPB & Appropriate (7.0) & Low \\
\hline & Procedural considerations & & \\
\hline 5 & $10-20 \mathrm{~mL}$ of absolute ethanol is recommended for EUS-CPN and the volume may be reduced in EUS-CGN & Appropriate (8.0) & High \\
\hline 6 & $\begin{array}{l}\text { Phenol may be used instead of alcohol for EUS-guided CPN in patients with alcohol intolerance due to aldehyde dehydrogenase } \\
\text { deficiency, but the comparative efficacy and safety of the two agents is uncertain }\end{array}$ & Appropriate (8.0) & Low \\
\hline 7 & $\begin{array}{l}\text { In order to perform EUS-CGN, the celiac ganglia can be identified between the aorta and the left adrenal gland in most patients. } \\
\text { Otherwise, they may be located cephalad to the origin of the celiac axis in others }\end{array}$ & Appropriate (8.0) & Moderate \\
\hline 9 & $\begin{array}{l}\text { When the ganglion cannot be identified, EUS-CPN is performed by single or bilateral injections but evidence is contradictory on } \\
\text { which approach is superior }\end{array}$ & Appropriate (8.5) & High \\
\hline 10 & EUS-guided CGN is recommended over single or bilateral injections around the celiac artery for improved pain relief & Appropriate (8.0) & High \\
\hline \multirow[t]{2}{*}{11} & Celiac broad plexus neurolysis may be associated with improved efficacy but routine use is not recommended & Appropriate (7.5) & Moderate \\
\hline & Management of complications & & \\
\hline 12 & The complications of EUS-CPN and CGN are generally minor and do not need specific treatment & Appropriate (8.0) & Low \\
\hline \multirow[t]{2}{*}{13} & Repeated injections for chronic pancreatitis should be avoided to prevent development of major complications & Appropriate (8.0) & Low \\
\hline & Competency and training & & \\
\hline 14 & Training in EUS-guided celiac plexus ablation is recommended in endoscopists experienced in EUS and EUS-FNA & Appropriate (9.0) & Very Low \\
\hline
\end{tabular}

CGN, celiac ganglia neurolysis; CPB, celiac plexus block; CPN, celiac plexus neurolysis. 
of pancreatic cancer experience pain, and pain control is a major challenge in the management of these patients. ${ }^{134}$

CPN has been shown to reduce pain scores and opioid consumption in patients with unresectable pancreatic cancers. ${ }^{135-137}$ Furthermore, CPN causes fewer adverse events than opioids. However, performing CPN in addition to pancreaticoduodenectomy did not result in a further reduction of pain, suggesting that the procedure should not be used in surgical candidates. ${ }^{138}$

\section{Statement 2}

EUS-guided CPN for treatment of pain arising from chronic pancreatitis is not recommended.

Statement is Appropriate (7.0)

Evidence level: Moderate

\section{Supporting evidence and comments}

The efficacy of EUS-CPN is relatively low for patients with pain arising from chronic pancreatitis. In a meta-analysis, EUS-CPN for pain in pancreatic cancer $(n=283)$ was compared with that for chronic pancreatitis $(n=376) .{ }^{139}$ The pooled proportion of patients with relief of pain was $80.12 \%$ in pancreatic cancer and $59.45 \%$ in chronic pancreatitis. In another meta-analysis of 11 relevant studies, EUS-CPN was effective in alleviating pain in $72.54 \%$ of patients with pancreatic cancer and $51.46 \%$ of patients with chronic pancreatitis. ${ }^{140}$ Similar findings were reported in a more recent meta-analysis. ${ }^{141}$ Thus, the role of EUS-CPN in chronic pancreatitis is still controversial due to the limited efficacy. If a trial of the procedure is planned, then a temporary block of the plexus using bupivacaine should be performed to observe for any effect in achieving pain relief.

\section{Optimal approach for ablation}

\section{Statement 3}

The EUS-guided approach is recommended over percutaneous image-guided techniques for celiac plexus ablation.

Statement is Appropriate (9.0)

Evidence level: Moderate

\section{Supporting evidence and comments}

The EUS-guided approach is performed under the guidance of precise real-time imaging. In addition, assessment with colour Doppler ultrasonography allows avoidance of injury to interposing blood vessels. Therefore, the approach is safer, more accurate and convenient than percutaneous image-guided approaches including radiographic, fluoroscopic, CT or transcutaneous ultrasonographic guidance. Only one study has compared the effectiveness of EUS-guided celiac plexus block (EU-CPB) with that of CT-guided CPB for chronic pancreatitis. ${ }^{142}$ The results showed that EUS-guided CPB provided more persistent pain relief than CT-guided CPB. However, only 10 patients were included for EUS-guided CPB and eight patients for CT-guided CPB. Nevertheless, given that the results of EUS-CPN are widely published and the procedure is continued to be practiced in many countries, the panel believes that the efficacy of the EUS and percutaneous approach should be at least comparable.

\section{Pre-procedural preparations}

\section{Statement 4}

Prophylactic antibiotics are suggested to be given when bupivacaine with steroids are used for EUS-CPB.

Statement is Appropriate (7.0)

Evidence level: Low

\section{Supporting evidence and comments}

In general, prophylactic antibiotics are not given before and after EUS-CPN. However, serious infectious complications such as peripancreatic abscess and retroperitoneal abscess are occasionally reported after injection of steroid in EUS-CPB in the setting of chronic pancreatitis. ${ }^{139} 143-145$ Therefore, prophylactic antibiotics are recommended before EUS-CPB when steroids are used. ${ }^{146}$ Antibiotics that cover enteric gram-negative organisms and enterococci should be used (second-generation cephalosporin or quinolone).

\section{Procedural considerations \\ Statement 5}

$10-20 \mathrm{~mL}$ of absolute ethanol is recommended for EUS-CPN and the volume may be reduced in EUS-guided celiac ganglia neurolysis (CGN).

Statement is Appropriate (8.0)

Evidence level: High

\section{Supporting evidence and comments}

Absolute ethanol is injected into the region until an echogenic cloud is seen to spread sufficiently under EUS. A total amount of $10-20 \mathrm{~mL}$ of ethanol is usually used in the EUS-CPN. In contrast, $1-2 \mathrm{~mL}$ of ethanol is usually used to inject the ganglion in EUS-CGN until it becomes hyperechoic and difficult to visualise. A randomised study showed that the total amount of injected ethanol was significantly lower in EUS-CGN than in EUS-CPN. ${ }^{147}$

\section{Statement 6}

Phenol may be used instead of alcohol for EUS-guided CPN in patients with alcohol intolerance due to aldehyde dehydrogenase deficiency, but the comparative efficacy and safety of the two agents is uncertain.

Statement is Appropriate (8.0)

Evidence level: Low

\section{Supporting evidence and comments}

Alcohol intolerance can be confirmed by an alcohol patch test which tests an individual for aldehyde dehydrogenase deficiency. ${ }^{148}$ Only one study has investigated the effectiveness of phenol instead of ethanol. ${ }^{149}$ In this study, phenol was used for six patients with alcohol intolerance and the effectiveness was compared with that of 16 patients without alcohol intolerance who received an ethanol injection. There was no significant difference in the positive response rate on day 7 and the rate of complications between the two groups. Further studies are required to evaluate the efficacy and safety of phenol.

\section{Statement 7}

In order to perform EUS-CGN, the celiac ganglia can be identified between the aorta and the left adrenal gland in most patients. Otherwise, they may be located cephalad to the origin of the celiac axis in others.

Statement is Appropriate (8.0)

Evidence Level: Moderate

\section{Supporting evidence and comments}

The celiac ganglia are most frequently seen to the left of the celiac artery, between the aorta and the left adrenal gland, at the level between the celiac artery and the left renal artery. They are also visualised cephalad to the celiac artery in some cases. They usually appear as hypoechoic nodular structures 
linked by hypoechoic threads residing in the periphery of this region. ${ }^{147150}$

\section{Efficacy of treatment \\ Statement 8}

Early EUS-CPN at the time of EUS-guided fine needle aspiration is recommended as it reduces pain and may moderate opioid consumption compared with best medical therapy.

Statement is Appropriate (7.5)

Evidence Level: High

\section{Supporting evidence and comments}

A study compared pain reduction and narcotic use after early EUS-CPN at the time of EUS with that of conventional pain management. ${ }^{151}$ They concluded that early EUS-CPN could reduce pain and may moderate morphine consumption in patients with painful inoperable pancreatic cancers.

\section{Statement 9}

When the ganglion cannot be identified, EUS-CPN is performed by single or bilateral injections but evidence is contradictory on which approach is superior.

Statement is Appropriate (8.5)

Evidence Level: High

\section{Supporting evidence and comments}

EUS-CPN is conventionally done with two approaches. ${ }^{152-154}$ The classic approach, known as the central technique, involves injection of the agent at the base of the celiac artery. The second approach, the bilateral technique, involves injecting the agent on both sides of the celiac artery. With improvements in ultrasound imaging technology, the celiac ganglion an now be visualised with EUS. ${ }^{155}$ The ganglion can be directly punctured for delivery of neurolytic agents resulting in celiac ganglion neurolysis (CGN). In addition, a modified technique for broad distribution of the agent was also reported. ${ }^{156}$ It involves injection around the superior mesenteric artery and celiac artery using a thin needle resulting in broad plexus neurolysis. A meta-analysis that included eight studies compared the treatment efficacy between unilateral and bilateral techniques. The rate of pain relief was significantly higher with bilateral injections compared with unilateral injections in patients with pancreatic cancer $(84.54 \%$ vs $45.99 \%){ }^{139}$ In another cohort study, the short-term safety and efficacy of central and bilateral EUS-CPN/EUS-CPB in 160 patients was assessed (71 treated centrally, 89 treated bilaterally). ${ }^{152}$ The mean reduction in pain score was significantly higher in patients treated with bilateral injections $(70.4 \%$ vs $45.9 \%$ ). A positive response ( $>50 \%$ reduction in pain score) was also significantly more frequent in the bilaterally treated group $(77.5 \%$ vs $50.7 \%)$. In addition, the only predictor of a positive response was the use of the bilateral procedure. These results suggested that the bilateral procedure was more effective than the central procedure. However, a randomised trial later showed no difference in pain relief between the central and bilateral techniques (central $69 \%$ vs bilateral $81 \% ; \mathrm{P}=0.340) .{ }^{153} \mathrm{In}$ addition, another retrospective study also showed similar pain reduction between the central and bilateral procedures. ${ }^{154}$ Thus, it is still controversial whether the bilateral approach is superior to the unilateral approach for relieving pain.

\section{Statement 10}

EUS-guided CGN is recommended over single or bilateral injections around the celiac artery for improved pain relief.
Statement is Appropriate (8.0)

Evidence Level: High

\section{Supporting evidence and comments}

The initial report of EUS-CGN showed a high response rate in a small group of patients. ${ }^{155}$ A retrospective comparative study then reported their data of EUS-CPN versus CGN. ${ }^{157}$ In the study, EUS-CGN was performed when the celiac ganglia were visible by EUS, otherwise bilateral EUS-CPN was performed. Multivariate analysis showed that patients with visible celiac ganglia were 15 times more likely to respond (OR 15.7; $\mathrm{P}=0.001)$. Subsequently, a multicentre randomised controlled trial was conducted to compare the efficacies of central EUS-CPN and EUS-CGN. The positive response rate was significantly higher in the EUS-CGN group $(73.5 \%$ vs $45.5 \%)$. The complete response rate was also significantly higher in the EUS-CGN group (50.0\% vs $18.2 \%)$.

\section{Statement 11}

Celiac broad plexus neurolysis may be associated with improved efficacy but routine use is not recommended.

Statement is Appropriate (7.5)

Evidence Level: Moderate

\section{Supporting evidence and comments}

A retrospective cohort study examined predictive factors for pain relief after EUS-CPN. ${ }^{158}$ Multivariate analysis revealed that direct invasion of the celiac plexus $(\mathrm{OR} 4.82, \mathrm{P}=0.0387)$ and distribution of ethanol only on the left side of the celiac artery (OR 8.67, $\mathrm{P}=0.0224$ ) were significant factors for a negative response to EUS-CPN. A study then assessed the effect of broad distribution of the neurolytic agent. ${ }^{156}$ In their retrospective study, they compared the effectiveness of standard EUS-CPN and EUS-guided broad plexus neurolysis (EUS-BPN). EUS-BPN involves injection along the celiac artery, superior mesenteric artery and inferior mesenteric artery using a thin 25-gauge needle. As a result, ethanol was distributed more widely and better pain relief was obtained in EUS-BPN than in EUS-CPN. These studies suggest that broad distribution of the injected ethanol was an important factor to predict the good response to EUS-CPN. However, the results of this study require further confirmation by other studies and it is uncertain whether such wide distribution of alcohol would result in any detrimental effects.

\section{Management of complications \\ Statement 12}

The complications of EUS-CPN and CGN are generally minor and do not need specific treatment.

Statement is Appropriate (8.0)

Evidence Level: Low

\section{Supporting evidence and comments}

Common reported adverse events of EUS-CPN include transient diarrhoea (0-23.4\%), transient pain exacerbation $(0-36 \%)$, transient hypotension $(0-33 \%)$ and inebriation $(0-12.5 \%) .{ }^{139} 140142-144147149151-167$ In most cases these events are mild and do not need specific treatment. In a randomised study of central EUS-CPN and EUS-CGN, the overall adverse events rates were similar between the two groups. ${ }^{147}$

\section{Statement 13}

Repeated injections for chronic pancreatitis should be avoided to prevent development of major complications. 
120

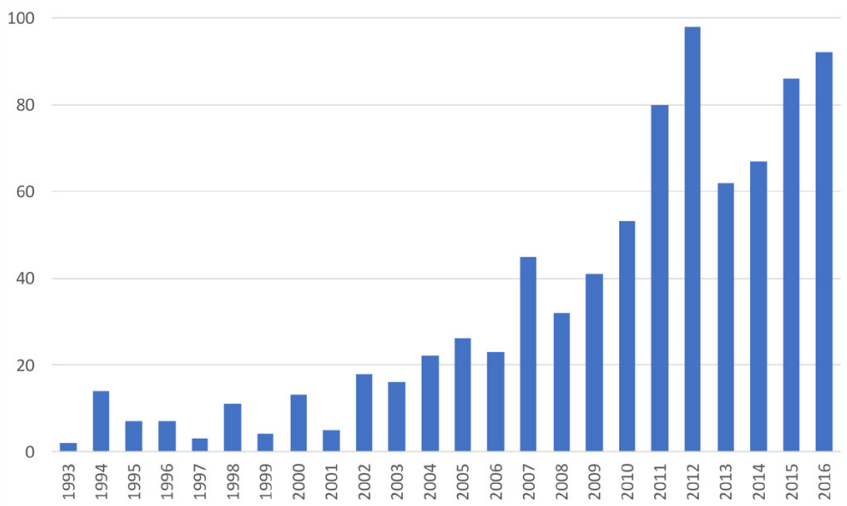

Figure 3 Number of publications on interventional endoscopic ultrasonography (EUS) each year

Statement is Appropriate (8.0)

Evidence Level: Low

\section{Supporting evidence and comments}

Severe adverse events such as retroperitoneal bleeding, abscess and ischaemia rarely occur after EUS-CPN or EUS-CPB. ${ }^{144} 145152$ 168-175 Most of these events, especially infectious ones, were reported in the setting of chronic pancreatitis. Retroperitoneal bleeding occurred in two cases who underwent the bilateral technique. ${ }^{152} 168$ Ischaemic events were lethal in three cases. ${ }^{172} 174175$ These vascular injuries and ischaemic events are probably due to injecting alcohol into an inappropriate site or an excessive number of sessions of EUS-CPN.

\section{Competency and training \\ Statement 14}

Training in EUS-guided celiac plexus ablation is recommended in endoscopists experienced in EUS and EUS-FNA.

Statement is Appropriate (9.0)

Evidence Level: Very Low

\section{Supporting evidence and comments}

EUS-CPN and CGN are relatively simple procedures. However, serious adverse events occasionally occur. Before and during the needle puncture, the target regions should be clearly visualised in a stable position. The needle tip should be visualised at all times during the puncture to avoid injury of vessels and other organs. Endoscopists who are competent in EUS-FNA would be able to perform the procedure provided that target regions are visualised.

\section{DISCUSSION}

EUS-guided drainage of a pancreatic pseudocyst was first reported in $1992 .{ }^{176}$ Since then, interventional EUS has undergone exponential growth throughout the past 20 years. Using the term 'interventional EUS' as a search criterion on PubMed, the number of publications each year has grown enormously (figure 3). Furthermore, new therapeutic procedures are reported every few years. The types of EUS interventional procedures have grown from those initially described by the EUS Working Group to now include gallbladder drainage, gastrointestinal anastomosis, portal vein interventions and tumour ablations. ${ }^{177-185}$
The current set of guidelines is the first published by an endoscopic society. Prior to formulation of the guidelines, the panel acknowledges the fact that evidence may be lacking in certain areas of the procedure. Thus, the RAM process was adopted to help formulate the guidelines. The rationale behind RAM is that randomised clinical trials are often not available or cannot provide evidence at a level of detail sufficient to apply to the wide range of patients seen in everyday clinical practice. Nevertheless, physicians will still need to make decisions every day about when to apply them. Thus, a method that could combine the best available scientific evidence with the collective judgement of experts to yield a statement regarding the appropriateness of performing a procedure at the level of patient-specific symptoms, medical history and test results is required. The strength of the instrument is that RAM has been shown to produce criteria that have excellent face, construct and predictive ability. ${ }^{186} 187$ Furthermore, studies comparing RAM results with subsequent randomised controlled trials have found excellent correlation. ${ }^{7}$

The current guidelines were developed on the four commonly performed therapeutic EUS procedures. An additional strength of the guidelines is that they focused on the technical aspects of the procedures and also addressed management issues before and after the intervention. Furthermore, competency and training issues were also discussed. All but one of the statements were found to be appropriate and necessary. This means that the expected benefits on following the guidelines exceeds the harms sufficiently that the service must be offered to the patient. Thus, the panel believes that the guidelines would be applicable to all those practising or learning interventional EUS procedures around the world. In addition, the guidelines could help standardise the elements involved with the procedures as wide variations in practice have been observed, and establishment of a consensus for safe practices is required. ${ }^{88}$

There are a number of limitations to the current guidelines. First, these EUS procedures are still in evolution and the devices used are not uniformly available across all countries. Hence, they should be adopted after consideration of device availability, institutional practices and endoscopist preferences. Second, the guidelines did not address outcome indicators of the procedures. The panel believes that this aspect should be addressed in future updates of the guidelines. When the procedures become more standardised, outcomes could be benchmarked across centres. In addition, since the learning curve in a few of the procedures is not established, concrete suggestions on the minimal number of procedures required to be performed in order to attain competency could not be provided. Lastly, the expert panel consisted mostly of interventional endosonographers and it is established that panels made up of members from the same discipline may rate more indications as appropriate than do panels composed of multiple specialties.

The current guidelines also identified a number of areas where randomised studies are urgently required to address the clinical questions. The use of EUS-specific metal stents in pseudocyst drainage needs to be justified due to its higher cost. The procedural characteristics of different EUS-BD procedures need to be better determined to understand which approach is the safest while providing the longest stent patency. Randomised studies comparing EUS-PD versus ERCP in surgical altered anatomy are required to understand which is the best approach in these challenging situations. Newer celiac plexus ablation techniques need to be evaluated in a multicentre setting to confirm the efficacy published in smaller studies.

The only other set of published guidelines on interventional EUS was provided by the European Federation of Societies for 
Ultrasound in Medicine and Biology (EFSUMB) in 2016. Interventional EUS was included as part of the set of guidelines under interventional ultrasound. Eight statements on EUS drainage of pancreatic fluid collections, six statements on EUS-BD and PD and eight statements on EUS-CPN were provided. Compared with the current guidelines, the guidelines published by EFSUMB were lacking in providing clear indications to the procedure, appraisal of the technical aspects, management of complications and competency and training $f$ the procedures. These deficiencies would limit the practical applicability in clinical practice.

In conclusion, the current guidelines on interventional EUS procedures are the first published by an endoscopic society. They provide an in-depth review of the current evidence and standardise the management of the procedures.

\section{Author affiliations}

'Department of Surgery, Prince of Wales Hospital, The Chinese University of Hong Kong, Hong Kong, Hong Kong

2Baldota Institute of Digestive Sciences, Mumbai, Maharashtra, India

${ }^{3}$ Department of Gastroenterology, Kitasato University Hospital, Sagamihara City, Japan

${ }^{4}$ Department of Gastroenterology, Teikyo University Mizonokuchi Hospital, Kawasaki, Japan

${ }^{5}$ Department of Gastroenterology, Changhai Hospital, Second Military Medical University, Shanghai, China

${ }^{6}$ Department of Gastroenterology, Asan Medical Center, Seoul, Republic of Korea

${ }^{7}$ Department of Gastroenterology, King Khalid University Hospital, King Saud University, Riyadh, Saudi Arabia

${ }^{8}$ Department of Gastroenterology and Hepatology, Changi General Hospital, Singapore

${ }^{9}$ Department of Gastroenterology, Aichi Cancer Center Hospital, Nagoya, Japan

${ }^{10}$ Department of Medicine, University of Malaya, Kuala Lumpur, Malaysia

${ }^{11}$ Department of Gastroenterology, Tokyo Medical University, Tokyo, Japan

${ }^{12}$ Department of Gastroenterology, Asian Institute of Gastroenterology, Hyderabad,

Telangana, India

${ }^{13}$ St Marianna University School of Medicine, Yokohama City Seibu Hospital, Kawasaki, Japan

${ }^{14}$ Department of Internal Medicine, Faculty of Medicine, Siriraj Hospital, Mahidol University, Bangkok, Thailand

${ }^{15}$ Department of Gastroenterology, Institute of Digestive and Hepatobiliary Sciences Medanta, The Medicity, Gurgaon, India

${ }^{16}$ Institute of Digestive Disease, Prince of Wales Hospital, The Chinese University of Hong Kong, Hong Kong, Hong Kong

${ }^{17}$ Department of Internal Medicine, National Taiwan University College of Medicine and Hospital, Taipei, Taiwan

${ }^{18}$ Department of Gastroenterology, Peking Union Medical College Hospital, Peking Union Medical College, Chinese Academy of Medical Sciences, Dongcheng-qu, Beijing, China

${ }^{19}$ Center for Interventional Endoscopy, Florida Hospital, Orlando, Florida, USA

${ }^{20}$ Department of Gastroenterology, Kyoto Second Red Cross Hospital, Kyoto, Japan

${ }^{21}$ Department of Medicine, National University of Singapore, Singapore

Contributors AYBT: Concept and design, voting member, data collection and analysis, drafting of the manuscript. VD: Concept and design, voting member, drafting of the manuscript. MK: Concept and design, voting member, drafting of the manuscript. IY: Concept and design, voting member, drafting of the manuscript. ZDJ: Voting member, critical review of the manuscript. DWS: Voting member, critical review of the manuscript. MA: Voting member, critical review of the manuscript. TLA: Voting member, critical review of the manuscript. $\mathrm{KH}$ : Voting member, critical review of the manuscript. IH: Voting member, critical review of the manuscript. TI: Voting member, critical review of the manuscript. SL: Voting member, critical review of the manuscript. KM: Voting member, critical review of the manuscript. NP: Voting member, review of the manuscript. RP: Voting member, critical review of the manuscript. RST: Voting member, critical review of the manuscript. H-PW: Voting member, critical review of the manuscript. AMY: Voting member, critical review of the manuscript. RH: Critical review of the manuscript. SV: Critical review of the manuscript. KY: Voting member, critical review of the manuscript. LKYH: Critical review of the manuscript, final approval of the manuscript.

Competing interests None declared.

Provenance and peer review Not commissioned; externally peer reviewed.

(c) Article author(s) (or their employer(s) unless otherwise stated in the text of the article) 2018. All rights reserved. No commercial use is permitted unless otherwise expressly granted.

\section{REFERENCES}

1 Hawes RH, Van Dam J, Varadarajulu S. EUS 2008 Working Group document: interventional EUS—a road map for the future. Gastrointest Endosc 2009;69:S1-2.

2 Fitch K, Bernstein SJ, Aguilar MD, et al; The RAND/UCLA Appropriateness Method User's Manual. Santa Barbara, CA: RAND Corporation, 2001.

3 Dixon M, Seevaratnam R, Wirtzfeld D, et al. A RAND/UCLA appropriateness study of the management of familial gastric cancer. Ann Surg Oncol 2013;20:533-41.

4 Gore ME, Bellmunt J, Eisen T, et al. Evaluation of treatment options for patients with advanced renal cell carcinoma: assessment of appropriateness, using the validated semi-quantitative RAND Corporation/University of California, Los Angeles methodology. Eur J Cancer 2012;48:1038-47.

5 Goodman KA, Patton CE, Fisher GA, et al. Appropriate customization of radiation therapy for stage II and III rectal cancer: executive summary of an ASTRO Clinical Practice Statement using the RAND/UCLA appropriateness method. Pract Radiat Oncol 2016;6:166-75.

6 Rudmik L, Soler ZM, Hopkins C, et al. Defining appropriateness criteria for endoscopic sinus surgery during management of uncomplicated adult chronic rhinosinusitis: a RAND/UCLA appropriateness study. Int Forum Allergy Rhinol 2016;6:557-67

7 Shekelle PG, Chassin MR, Park RE. Assessing the predictive validity of the RAND/ UCLA appropriateness method criteria for performing carotid endarterectomy. Int $J$ Technol Assess Health Care 1998;14:707-27.

8 Broder MS, Kanouse DE, Mittman BS, et al. The appropriateness of recommendations for hysterectomy. Obstet Gynecol 2000;95:199-205.

9 Kahan JP, Bernstein SJ, Leape LL, et al. Measuring the necessity of medical procedures. Med Care 1994;32:357-65.

10 Teoh AY, Dhir V, Jin ZD, et al. Systematic review comparing endoscopic, percutaneous and surgical pancreatic pseudocyst drainage. World I Gastrointest Endosc 2016:8:310-8.

11 Dhir V, Isayama H, Itoi T, et al. Endoscopic ultrasonography-guided biliary and pancreatic duct interventions. Dig Endosc 2017;29:472-85.

12 Ang TL, Teoh AYB. Endoscopic ultrasonography-guided drainage of pancreatic fluid collections. Dig Endosc 2017;29:463-71.

13 Yasuda I, Wang HP. Endoscopic ultrasound-guided celiac plexus block and neurolysis. Dig Endosc 2017;29:455-62.

14 Guyatt GH, Oxman AD, Schünemann HJ, et al. GRADE guidelines: a new series of articles in the Journal of Clinical Epidemiology. J Clin Epidemiol 2011;64:380-2.

15 Cui ML, Kim KH, Kim HG, et al. Incidence, risk factors and clinical course of pancreatic fluid collections in acute pancreatitis. Dig Dis Sci 2014;59:1055-62.

16 Diculescu M, Ciocîlan M, Ciocîrlan M, et al. Predictive factors for pseudocysts and peripancreatic collections in acute pancreatitis. Rom I Gastroenterol 2005;14:129-34

17 London NJ, Neoptolemos JP, Lavelle J, et al. Serial computed tomography scanning in acute pancreatitis: a prospective study. Gut 1989;30:397-403.

18 Kourtesis G, Wilson SE, Williams RA. The clinical significance of fluid collections in acute pancreatitis. Am Surg 1990;56:796-9.

19 Banks PA, Bollen TL, Dervenis C, et al. Classification of acute pancreatitis--2012: revision of the Atlanta classification and definitions by international consensus. Gut 2013;62:102-11.

20 Yeo CJ, Bastidas JA, Lynch-Nyhan A, et al. The natural history of pancreatic pseudocysts documented by computed tomography. Surg Gynecol Obstet 1990;170:411-7.

21 Bradley EL, Clements JL, Gonzalez AC. The natural history of pancreatic pseudocysts: a unified concept of management. Am J Surg 1979;137:135-41.

22 Maule WF, Reber HA. Diagnosis and Management of Pancreatic Pseudocysts, Pancreatic Ascites, and Pancreatic Fistulas. In: Go VLW, Dimagno EP, eds. The Pancreas: Biology, Pathobiology, and Disease. 2nd Edn: Raven Press, 1993.

23 Gurusamy KS, Pallari E, Hawkins N, et al. Management strategies for pancreatic pseudocysts. Cochrane Database Syst Rev 2016;4:CD011392.

24 Varadarajulu S, Bang JY, Sutton BS, et al. Equal efficacy of endoscopic and surgical cystogastrostomy for pancreatic pseudocyst drainage in a randomized trial. Gastroenterology 2013;145:583-90

25 Melman L, Azar R, Beddow K, et al. Primary and overall success rates for clinical outcomes after laparoscopic, endoscopic, and open pancreatic cystgastrostomy for pancreatic pseudocysts. Surg Endosc 2009;23:267-71.

26 Varadarajulu S, Lopes TL, Wilcox CM, et al. EUS versus surgical cystgastrostomy for management of pancreatic pseudocysts. Gastrointest Endosc 2008;68:649-55

27 Park DH, Lee SS, Moon SH, et al. Endoscopic ultrasound-guided versus conventional transmural drainage for pancreatic pseudocysts: a prospective randomized trial. Endoscopy 2009:41:842-8

28 Sauer B, Kahaleh M. Prospective randomized trial comparing EUS and EGD for transmural drainage of pancreatic pseudocysts: a need for a large randomized study. Gastrointest Endosc 2010;71:432-3.

29 Varadarajulu S, Christein JD, Tamhane A, et al. Prospective randomized trial comparing EUS and EGD for transmural drainage of pancreatic pseudocysts (with videos). Gastrointest Endosc 2008;68:1102-11. 
30 Morton JM, Brown A, Galanko JA, et al. A national comparison of surgical versus percutaneous drainage of pancreatic pseudocysts: 1997-2001. J Gastrointest Surg 2005;9:15-21.

31 Heider R, Meyer AA, Galanko JA, et al. Percutaneous drainage of pancreatic pseudocysts is associated with a higher failure rate than surgical treatment in unselected patients. Ann Surg 1999;229:781-7.

32 Adams DB, Anderson MC. Percutaneous catheter drainage compared with internal drainage in the management of pancreatic pseudocyst. Ann Surg 1992;215:571-8.

33 Lang EK, Paolini RM, Pottmeyer A. The efficacy of palliative and definitive percutaneous versus surgical drainage of pancreatic abscesses and pseudocysts: a prospective study of 85 patients. South Med J 1991;84:55-64.

34 Kahaleh M, Shami VM, Conaway MR, et al. Endoscopic ultrasound drainage of pancreatic pseudocyst: a prospective comparison with conventional endoscopic drainage. Endoscopy 2006;38:355-9.

35 Bhasin DK, Rana SS, Nanda M, et al. Endoscopic management of pancreatic pseudocysts at atypical locations. Surg Endosc 2010;24:1085-91.

36 Gupta R, Munoz JC, Garg P, et al. Mediastinal pancreatic pseudocyst: a case report and review of the literature. MedGenMed 2007;9:8.

37 Topa L, László F, Sahin P, et al. Endoscopic transgastric drainage of a pancreatic pseudocyst with mediastinal and cervical extensions. Gastrointest Endosc 2006;64:460-3.

38 Morgan DE, Baron TH, Smith JK, et al. Pancreatic fluid collections prior to intervention: evaluation with MR imaging compared with CT and US. Radiology 1997:203:773-8.

39 Delcenserie R, Yzet T, Ducroix JP. Prophylactic antibiotics in treatment of severe acute alcoholic pancreatitis. Pancreas 1996;13:198-201.

40 Isenmann R, Rünzi M, Kron M, et al. Prophylactic antibiotic treatment in patients with predicted severe acute pancreatitis: a placebo-controlled, double-blind trial. Gastroenterology 2004;126:997-1004.

41 Nordback I, Sand J, Saaristo R, et al. Early treatment with antibiotics reduces the need for surgery in acute necrotizing pancreatitis--a single-center randomized study. J Gastrointest Surg 2001;5:113-9. discussion 118-20.

42 Pederzoli P, Bassi C, Vesentini S, et al. A randomized multicenter clinical trial of antibiotic prophylaxis of septic complications in acute necrotizing pancreatitis with imipenem. Surg Gynecol Obstet 1993;176:480-3.

43 Sainio V, Kemppainen E, Puolakkainen P, et al. Early antibiotic treatment in acute necrotising pancreatitis. Lancet 1995;346:663-7.

44 Villatoro E, Mulla M, Larvin M. Antibiotic therapy for prophylaxis against infection of pancreatic necrosis in acute pancreatitis. Cochrane Database Syst Rev 2010:CD002941.

45 Dellinger EP, Tellado JM, Soto NE, et al. Early antibiotic treatment for severe acute necrotizing pancreatitis: a randomized, double-blind, placebo-controlled study. Ann Surg 2007;245:674-83.

46 Wyse JM, Paquin SC, Sahai A. Fluid collection drainage via transmural endoscopic ultrasound (EUS) guided insertion of multiple stents without fluoroscopic assistance. Gastrointest Endosc 2009:69:AB326.

47 Seicean A, Stan-luga R, Badea R, et al. The safety of endoscopic ultrasonographyguided drainage of pancreatic fluid collections without fluoroscopic control: a single tertiary center experience. J Gastrointestin Liver Dis 2011;20:39-45.

48 Bang JY, Hawes R, Bartolucci A, et al. Efficacy of metal and plastic stents for transmural drainage of pancreatic fluid collections: a systematic review. Dig Endosc 2015;27:486-98

49 Bang JY, Wilcox CM, Trevino JM, et al. Relationship between stent characteristics and treatment outcomes in endoscopic transmural drainage of uncomplicated pancreatic pseudocysts. Surg Endosc 2014;28:2877-83.

50 Berzosa M, Maheshwari S, Patel KK, et al. Single-step endoscopic ultrasonographyguided drainage of peripancreatic fluid collections with a single self-expandable metal stent and standard linear echoendoscope. Endoscopy 2012;44:543-7.

51 Fabbri C, Luigiano C, Cennamo V, et al. Endoscopic ultrasound-guided transmural drainage of infected pancreatic fluid collections with placement of covered selfexpanding metal stents: a case series. Endoscopy 2012;44:429-33.

52 Penn DE, Draganov PV, Wagh MS, et al. Prospective evaluation of the use of fully covered self-expanding metal stents for EUS-guided transmural drainage of pancreatic pseudocysts. Gastrointest Endosc 2012;76:679-84.

53 Talreja JP, Shami VM, Ku J, et al. Transenteric drainage of pancreatic-fluid collections with fully covered self-expanding metallic stents (with video). Gastrointest Endosc 2008;68:1199-203.

54 Weilert F, Binmoeller KF, Shah JN, et al. Endoscopic ultrasound-guided drainage of pancreatic fluid collections with indeterminate adherence using temporary covered metal stents. Endoscopy 2012:44:780-3

55 Gornals JB, De la Serna-Higuera C, Sánchez-Yague A, et al. Endosonography-guided drainage of pancreatic fluid collections with a novel lumen-apposing stent. Surg Endosc 2013;27:1428-34.

56 Itoi T, Binmoeller KF, Shah J, et al. Clinical evaluation of a novel lumen-apposing metal stent for endosonography-guided pancreatic pseudocyst and gallbladder drainage (with videos). Gastrointest Endosc 2012;75:870-6.

57 Dhir V, Teoh AY, Bapat M, et al. EUS-guided pseudocyst drainage: prospective evaluation of early removal of fully covered self-expandable metal stents with pancreatic ductal stenting in selected patients. Gastrointest Endosc 2015;82:650-7. quiz 718 e1-5.

58 Moon JH, Choi HJ, Kim DC, et al. A newly designed fully covered metal stent for lumen apposition in EUS-guided drainage and access: a feasibility study (with videos). Gastrointest Endosc 2014;79:990-5.

59 Rinninella E, Kunda R, Dollhopf $M$, et al. EUS-guided drainage of pancreatic fluid collections using a novel lumen-apposing metal stent on an electrocautery-enhanced delivery system: a large retrospective study (with video). Gastrointest Endosc 2015;82:1039-46.

60 Siddiqui AA, Adler DG, Nieto J, et al. EUS-guided drainage of peripancreatic fluid collections and necrosis by using a novel lumen-apposing stent: a large retrospective, multicenter U.S. experience (with videos). Gastrointest Endosc 2016:83:699-707.

61 Vazquez-Sequeiros E, Baron TH, Pérez-Miranda M, et al. Evaluation of the short- and long-term effectiveness and safety of fully covered self-expandable metal stents for drainage of pancreatic fluid collections: results of a Spanish nationwide registry. Gastrointest Endosc 2016:84:450-7.

62 Bang JY, Hasan M, Navaneethan U, et al. Lumen-apposing metal stents (LAMS) for pancreatic fluid collection (PFC) drainage: may not be business as usual. Gut 2017:66:2054-6.

63 Teoh AY, Ng EK, Chan SM, et al. Ex vivo comparison of the lumen-apposing properties of EUS-specific stents (with video). Gastrointest Endosc 2016;84:62-8.

64 Neoptolemos JP, London NJ, Carr-Locke DL. Assessment of main pancreatic duct integrity by endoscopic retrograde pancreatography in patients with acute pancreatitis. Br J Surg 1993;80:94-9.

65 Lau ST, Simchuk EJ, Kozarek RA, et al. A pancreatic ductal leak should be sought to direct treatment in patients with acute pancreatitis. Am J Surg 2001;181:411-5.

66 Jang JW, Kim MH, Oh D, et al. Factors and outcomes associated with pancreatic duct disruption in patients with acute necrotizing pancreatitis. Pancreatology 2016:16:958-65.

67 Kozarek RA, Ball TJ, Patterson DJ, et al. Endoscopic transpapillary therapy for disrupted pancreatic duct and peripancreatic fluid collections. Gastroenterology 1991:100:1362-70.

68 Bracher GA, Manocha AP, DeBanto JR, et al. Endoscopic pancreatic duct stenting to treat pancreatic ascites. Gastrointest Endosc 1999:49:710-5.

69 Varadarajulu S, Noone TC, Tutuian R, et al. Predictors of outcome in pancreatic duct disruption managed by endoscopic transpapillary stent placement. Gastrointest Endosc 2005;61:568-75.

70 Telford JJ, Farrell JJ, Saltzman JR, et al. Pancreatic stent placement for duct disruption. Gastrointest Endosc 2002;56:18-24.

71 Trevino JM, Tevino JM, Tamhane A, Varadarajulu S, et al. Successful stenting in ductal disruption favorably impacts treatment outcomes in patients undergoing transmural drainage of peripancreatic fluid collections. J Gastroenterol Hepatol 2010:25:526-31.

72 Brennan PM, Stefaniak T, Palmer KR, et al. Endoscopic transpapillary stenting of pancreatic duct disruption. Dig Surg 2006;23:250-4.

73 Rana SS, Bhasin DK, Nanda M, et al. Endoscopic transpapillary drainage for external fistulas developing after surgical or radiological pancreatic interventions. $J$ Gastroenterol Hepatol 2010;25:1087-92.

74 Tanaka T, Kuroki T, Kitasato A, et al. Endoscopic transpapillary pancreatic stenting for internal pancreatic fistula with the disruption of the pancreatic ductal system. Pancreatology 2013;13:621-4.

75 Bhasin DK, Rana SS, Udawat HP, et al. Management of multiple and large pancreatic pseudocysts by endoscopic transpapillary nasopancreatic drainage alone. Am J Gastroenterol 2006:101:1780-6.

76 Arvanitakis M, Delhaye M, Bali MA, et al. Pancreatic-fluid collections: a randomized controlled trial regarding stent removal after endoscopic transmural drainage. Gastrointest Endosc 2007;65:609-19.

77 Itoi T, Itokawa F, Tsuchiya T, et al. EUS-guided pancreatic pseudocyst drainage: simultaneous placement of stents and nasocystic catheter using double-guidewire technique. Dig Endosc 2009;21(Suppl 1):S53-6.

78 Siddiqui AA, Dewitt JM, Strongin A, et al. Outcomes of EUS-guided drainage of debris-containing pancreatic pseudocysts by using combined endoprosthesis and a nasocystic drain. Gastrointest Endosc 2013;78:589-95.

79 Puri R, Mishra SR, Thandassery RB, et al. Outcome and complications of endoscopic ultrasound guided pancreatic pseudocyst drainage using combined endoprosthesis and naso-cystic drain. J Gastroenterol Hepatol 2012;27:722-7.

80 Yuan H, Qin M, Liu R, et al. Single-step versus 2-step management of huge pancreatic pseudocysts: a prospective randomized trial with long-term follow-up. Pancreas 2015:44:570-3.

81 Lakhtakia S, Basha J, Talukdar R, et al. Endoscopic "step-up approach" using a dedicated biflanged metal stent reduces the need for direct necrosectomy in walledoff necrosis (with videos). Gastrointest Endosc 2017:85:1243-52.

82 Cahen D, Rauws E, Fockens P, et al. Endoscopic drainage of pancreatic pseudocysts: long-term outcome and procedural factors associated with safe and successful treatment. Endoscopy 2005;37:977-83.

83 Adams DB, Zellner JL, Anderson MC. Arterial hemorrhage complicating pancreatic pseudocysts: role of angiography. J Surg Res 1993;54:150-6. 
84 Parodi A, Repici A, Pedroni A, et al. Endoscopic management of GI perforations with a new over-the-scope clip device (with videos). Gastrointest Endosc 2010;72:881-6.

85 Sharaiha RZ, Kumta NA, DeFilippis EM, et al. A large multicenter experience with endoscopic suturing for management of gastrointestinal defects and stent anchorage in 122 patients: a retrospective review. J Clin Gastroenterol 2016;50:388-92.

86 Wang MH, Dy F, Vu VK, et al. Structured endoscopic ultrasonography (EUS) training program improved knowledge and skills of trainees: Results from the Asian EUS Group. Dig Endosc 2015;27:687-91.

87 Baron TH, DeSimio TM. New ex-vivo porcine model for endoscopic ultrasoundguided training in transmural puncture and drainage of pancreatic cysts and fluid collections (with videos). Endosc Ultrasound 2015;4:34-9.

88 Teoh AY, Ho LK, Dhir VK, et al. A multi-institutional survey on the practice of endoscopic ultrasound (EUS) guided pseudocyst drainage in the Asian EUS group. Endosc Int Open 2015:3:E130-3.

89 Harewood GC, Wright CA, Baron TH. Impact on patient outcomes of experience in the performance of endoscopic pancreatic fluid collection drainage. Gastrointest Endosc 2003;58:230-5.

90 Varadarajulu S, Tamhane A, Blakely J. Graded dilation technique for EUS-guided drainage of peripancreatic fluid collections: an assessment of outcomes and complications and technical proficiency (with video). Gastrointest Endosc 2008;68:656-66.

91 Artifon EL, Aparicio D, Paione JB, et al. Biliary drainage in patients with unresectable, malignant obstruction where ERCP fails: endoscopic ultrasonography-guided choledochoduodenostomy versus percutaneous drainage. J Clin Gastroenterol 2012:46:768-74.

92 Khan MA, Akbar A, Baron TH, et al. Endoscopic ultrasound-guided biliary drainage: a systematic review and meta-analysis. Dig Dis Sci 2016:61:684-703.

93 Wang K, Zhu J, Xing L, et al. Assessment of efficacy and safety of EUS-guided biliary drainage: a systematic review. Gastrointest Endosc 2016:83:1218-27.

94 Lee $\mathrm{TH}$, Choi JH, Park doH, et al. Similar efficacies of endoscopic ultrasound-guided transmural and percutaneous drainage for malignant distal biliary obstruction. Clin Gastroenterol Hepatol 2016:14:1011-9.

95 Artifon EL, Loureiro JF, Baron TH, et al. Surgery or EUS-guided choledochoduodenostomy for malignant distal biliary obstruction after ERCP failure. Endosc Ultrasound 2015;4:235-43.

96 Inamdar S, Slattery E, Sejpal DV, et al. Systematic review and meta-analysis of singleballoon enteroscopy-assisted ERCP in patients with surgically altered $\mathrm{Gl}$ anatomy. Gastrointest Endosc 2015:82:9-19.

97 Khashab MA, El Zein MH, Sharzehi K, et al. EUS-guided biliary drainage or enteroscopy-assisted ERCP in patients with surgical anatomy and biliary obstruction: an international comparative study. Endosc Int Open 2016;4:E1322-E1327.

98 Kahaleh M, Artifon EL, Perez-Miranda M, et al. Endoscopic ultrasonography guided biliary drainage: summary of consortium meeting, May 7th, 2011, Chicago. World J Gastroenterol 2013;19:1372-9.

99 Chan SM, Teoh AY. Endoscopic ultrasound-guided biliary drainage: a review. Curr Treat Options Gastroenterol 2015;13:171-84.

100 Khashab MA, Messallam AA, Penas I, et al. International multicenter comparative trial of transluminal EUS-guided biliary drainage via hepatogastrostomy vs. choledochoduodenostomy approaches. Endosc Int Open 2016:4:E175-E181.

101 Ogura T, Sano T, Onda S, et al. Endoscopic ultrasound-guided biliary drainage for right hepatic bile duct obstruction: novel technical tips. Endoscopy 2015;47:72-5.

102 Artifon EL, Marson FP, Gaidhane M, et al. Hepaticogastrostomy or choledochoduodenostomy for distal malignant biliary obstruction after failed ERCP is there any difference? Gastrointest Endosc 2015:81:950-9.

103 Andriulli A, Loperfido S, Napolitano G, et al. Incidence rates of post-ERCP complications: a systematic survey of prospective studies. Am J Gastroenterol 2007; 102:1781-8.

104 Boender J, Nix GA, de Ridder MA, et al. Endoscopic sphincterotomy and biliary drainage in patients with cholangitis due to common bile duct stones. Am J Gastroenterol 1995:90:233-8.

105 Freeman ML, Overby C. Selective MRCP and CT-targeted drainage of malignant hilar biliary obstruction with self-expanding metallic stents. Gastrointest Endosc 2003:58:41-9.

106 Brand M, Bizos D, O'Farrell P. Antibiotic prophylaxis for patients undergoing elective endoscopic retrograde cholangiopancreatography. Cochrane Database Syst Rev 2010:CD007345

107 Kumbhari V, Peñas I, Tieu AH, et al. Interventional EUS using a flexible 19-gauge needle: an international multicenter experience in 162 patients. Dig Dis SCi 2016:61:3552-9.

108 Dhir V, Kwek BE, Bhandari S, et al. EUS-guided biliary rendezvous using a short hydrophilic guidewire. J Interv Gastroenterol 2011;1:153-9.

109 Park DH, Jang JW, Lee SS, et al. EUS-guided biliary drainage with transluminal stenting after failed ERCP: predictors of adverse events and long-term results. Gastrointest Endosc 2011:74:1276-84.

110 Attili F, Rimbaş M, Galasso D, et al. Fluoroless endoscopic ultrasound-guided biliary drainage after failed ERCP with a novel lumen-apposing metal stent mounted on a cautery-tipped delivery system. Endoscopy 2015;47(Suppl 1):E619-20.
111 Kunda R, Pérez-Miranda M, Will U, et al. EUS-guided choledochoduodenostomy for malignant distal biliary obstruction using a lumen-apposing fully covered metal stent after failed ERCP. Surg Endosc 2016;30:5002-8

112 Park DH, Lee TH, Paik WH, et al. Feasibility and safety of a novel dedicated device for one-step EUS-guided biliary drainage: a randomized trial. J Gastroenterol Hepatol 2015;30:1461-6.

113 Gupta K, Perez-Miranda M, Kahaleh M, et al. Endoscopic ultrasound-assisted bile duct access and drainage: multicenter, long-term analysis of approach, outcomes, and complications of a technique in evolution. J Clin Gastroenterol 2014;48:80-7.

114 Minaga K, Kitano M, Yamashita Y, et al. Stent migration into the abdominal cavity after EUS-guided hepaticogastrostomy. Gastrointest Endosc 2017;85:263-4.

115 Lee TH, Choi JH, Lee SS, et al. A pilot proof-of-concept study of a modified device for one-step endoscopic ultrasound-guided biliary drainage in a new experimental biliary dilatation animal model. World J Gastroenterol 2014:20:5859-66

116 Dhir V, Itoi T, Fockens P, et al. Novel ex vivo model for hands-on teaching of and training in EUS-guided biliary drainage: creation of "Mumbai EUS" stereolithography/3D printing bile duct prototype (with videos). Gastrointest Endosc 2015;81:440-6.

117 Itoi T, Kasuya K, Sofuni A, et al. Endoscopic ultrasonography-guided pancreatic duct access: techniques and literature review of pancreatography, transmural drainage and rendezvous techniques. Dig Endosc 2013;25:241-52.

118 Fujii-Lau LL, Levy MJ. Endoscopic ultrasound-guided pancreatic duct drainage. J Hepatobiliary Pancreat Sci 2015;22:51-7.

119 Schreiner MA, Chang L, Gluck M, et al. Laparoscopy-assisted versus balloon enteroscopy-assisted ERCP in bariatric post-Roux-en-Y gastric bypass patients. Gastrointest Endosc 2012;75:748-56

120 Shah RJ, Smolkin M, Yen R, et al. A multicenter, U.S. experience of single-balloon, double-balloon, and rotational overtube-assisted enteroscopy ERCP in patients with surgically altered pancreaticobiliary anatomy (with video). Gastrointest Endosc 2013;77:593-600.

121 Chen YI, Levy MJ, Moreels TG, et al. An international multicenter study comparing EUS-guided pancreatic duct drainage with enteroscopy-assisted endoscopic retrograde pancreatography after Whipple surgery. Gastrointest Endosc 2017:85:170-7.

122 Shimatani M, Hatanaka H, Kogure H, et al. Diagnostic and therapeutic endoscopic retrograde cholangiography using a short-type double-balloon endoscope in patients with altered gastrointestinal anatomy: a multicenter prospective study in Japan. Am J Gastroenterol 2016:111:1750-8.

123 Yane K, Katanuma A, Maguchi H, et al. Short-type single-balloon enteroscopeassisted ERCP in postsurgical altered anatomy: potential factors affecting procedural failure. Endoscopy 2017;49:69-74.

124 François E, Kahaleh M, Giovannini M, et al. EUS-guided pancreaticogastrostomy. Gastrointest Endosc 2002:56:128-33.

125 Kahaleh M, Yoshida C, Yeaton P. EUS antegrade pancreatography with gastropancreatic duct stent placement: review of two cases. Gastrointest Endosc 2003;58:919-23.

126 Will U, Meyer F, Manger T, et al. Endoscopic ultrasound-assisted rendezvous maneuver to achieve pancreatic duct drainage in obstructive chronic pancreatitis. Endoscopy 2005:37:171-3.

127 Tessier G, Bories E, Arvanitakis M, et al. EUS-guided pancreatogastrostomy and pancreatobulbostomy for the treatment of pain in patients with pancreatic ductal dilatation inaccessible for transpapillary endoscopic therapy. Gastrointest Endosc 2007:65:233-41

128 Tyberg A, Sharaiha RZ, Kedia P, et al. EUS-guided pancreatic drainage for pancreatic strictures after failed ERCP: a multicenter international collaborative study. Gastrointest Endosc 2017:85:164-9.

129 Chapman CG, Waxman I, Siddiqui UD. Endoscopic ultrasound (EUS)-guided pancreatic duct drainage: the basics of when and how to perform EUS-guided pancreatic duct interventions. Clin Endosc 2016;49:161-7.

130 Itoi T, Sofuni A, Tsuchiya T, et al. Initial evaluation of a new plastic pancreatic duct stent for endoscopic ultrasonography-guided placement. Endoscopy 2015;47:462-5.

131 Fujii LL, Topazian MD, Abu Dayyeh BK, et al. EUS-guided pancreatic duct intervention: outcomes of a single tertiary-care referral center experience. Gastrointest Endosc 2013;78:854-64.

132 Oh D, Park DH, Cho MK, et al. Feasibility and safety of a fully covered selfexpandable metal stent with antimigration properties for EUS-guided pancreatic duct drainage: early and midterm outcomes (with video). Gastrointest Endosc 2016;83:366-73

133 Alvarez-Sánchez MV, Jenssen C, Faiss S, et al. Interventional endoscopic ultrasonography: an overview of safety and complications. Surg Endosc 2014:28:712-34

134 Caraceni A, Portenoy RK. Pain management in patients with pancreatic carcinoma. Cancer 1996:78:639-53.

135 Zhong W, Yu Z, Zeng JX, et al. Celiac plexus block for treatment of pain associated with pancreatic cancer: a meta-analysis. Pain Pract 2014;14:43-51.

136 Nagels W, Pease N, Bekkering G, et al. Celiac plexus neurolysis for abdominal cancer pain: a systematic review. Pain Med 2013;14:1140-63. 
137 Arcidiacono PG, Calori G, Carrara S, et al. Celiac plexus block for pancreatic cancer pain in adults. Cochrane Database Syst Rev 2011:CD007519.

138 Lavu H, Lengel HB, Sell NM, et al. A prospective, randomized, double-blind, placebo controlled trial on the efficacy of ethanol celiac plexus neurolysis in patients with operable pancreatic and periampullary adenocarcinoma. J Am Coll Surg 2015;220:497-508.

139 Puli SR, Reddy JB, Bechtold ML, et al. EUS-guided celiac plexus neurolysis for pain due to chronic pancreatitis or pancreatic cancer pain: a meta-analysis and systematic review. Dig Dis Sci 2009;54:2330-7.

140 Kaufman M, Singh G, Das S, et al. Efficacy of endoscopic ultrasound-guided celiac plexus block and celiac plexus neurolysis for managing abdominal pain associated with chronic pancreatitis and pancreatic cancer. J Clin Gastroenterol 2010:44:127-34

141 Moura RN, De Moura EG, Bernardo WM, et al. Endoscopic-ultrasound versus percutaneous-guided celiac plexus block for chronic pancreatitis pain. A systematic review and meta-analysis. Rev Gastroenterol Peru 2015;35:333-41.

142 Gress F, Schmitt C, Sherman S, et al. A prospective randomized comparison of endoscopic ultrasound- and computed tomography-guided celiac plexus block for managing chronic pancreatitis pain. Am J Gastroenterol 1999:94:900-5.

143 Gress F, Schmitt C, Sherman S, et al. Endoscopic ultrasound-guided celiac plexus block for managing abdominal pain associated with chronic pancreatitis: a prospective single center experience. Am I Gastroenterol 2001;96:409-16.

144 O'Toole TM, Schmulewitz N. Complication rates of EUS-guided celiac plexus blockade and neurolysis: results of a large case series. Endoscopy 2009:41:593-7.

145 Mahajan R, Nowell W. Theerathorn P. Empyema after endoscopic ultrasound guided celiac plexus pain block (EUS-CBP) in chronic pancreatitis: experience at an academic center. Gastrointest Endosc 2002:55:AB101.

146 Fusaroli P, Jenssen C, Hocke M, et al. EFSUMB Guidelines on Interventional Ultrasound (INVUS). Part V: EUS-guided therapeutic interventions (short version). Ultraschall Med 2016;37:412-20.

147 Doi S, Yasuda I, Kawakami H, et al. Endoscopic ultrasound-guided celiac ganglia neurolysis vs. celiac plexus neurolysis: a randomized multicenter trial. Endoscopy 2013;45:362-9.

148 Higuchi S, Muramatsu T, Saito M, et al. Ethanol patch test for low Km aldehyde dehydrogenase deficiency. Lancet 1987;1:629.

149 Ishiwatari H, Hayashi T, Yoshida M, et al. Phenol-based endoscopic ultrasound-guided celiac plexus neurolysis for East Asian alcohol-intolerant upper gastrointestinal cancer patients: a pilot study. World I Gastroenterol 2014;20:10512-7.

150 Levy M, Rajan E, Keeney G, et al. Neural ganglia visualized by endoscopic ultrasound. Am J Gastroenterol 2006:101:1787-91.

151 Wyse JM, Carone M, Paquin SC, et al. Randomized, double-blind, controlled trial of early endoscopic ultrasound-guided celiac plexus neurolysis to prevent pain progression in patients with newly diagnosed, painful, inoperable pancreatic cancer. J Clin Oncol 2011:29:3541-6.

152 Sahai AV, Lemelin V, Lam E, et al. Central vs. bilateral endoscopic ultrasound-guided celiac plexus block or neurolysis: a comparative study of short-term effectiveness. Am J Gastroenterol 2009;104:326-9.

153 LeBlanc JK, Al-Haddad M, McHenry L, et al. A prospective, randomized study of EUS-guided celiac plexus neurolysis for pancreatic cancer: one injection or two? Gastrointest Endosc 2011;74:1300-7.

154 Téllez-Ávila FI, Romano-Munive AF, Herrera-Esquivel JJ, et al. Central is as effective as bilateral endoscopic ultrasound-guided celiac plexus neurolysis in patients with unresectable pancreatic cancer. Endosc Ultrasound 2013:2:153-6.

155 Levy MJ, Topazian MD, Wiersema MJ, et al. Initial evaluation of the efficacy and safety of endoscopic ultrasound-quided direct ganglia neurolysis and block. Am J Gastroenterol 2008;103:98-103.

156 Sakamoto H, Kitano M, Kamata K, et al. EUS-guided broad plexus neurolysis over the superior mesenteric artery using a 25-gauge needle. Am J Gastroenterol 2010:105:2599-606

157 Ascunce G, Ribeiro A, Reis I, et al. EUS visualization and direct celiac ganglia neurolysis predicts better pain relief in patients with pancreatic malignancy (with video). Gastrointest Endosc 2011;73:267-74

158 Iwata K, Yasuda I, Enya M, et al. Predictive factors for pain relief after endoscopic ultrasound-guided celiac plexus neurolysis. Dig Endosc 2011;23:140-5.

159 Wiersema MJ, Wiersema LM. Endosonography-guided celiac plexus neurolysis. Gastrointest Endosc 1996:44:656-62.

160 Ishiwatari H, Hayashi T, Yoshida M, et al. EUS-guided celiac plexus neurolysis by using highly viscous phenol-glycerol as a neurolytic agent (with video). Gastrointest Endosc 2015;81:479-83.

161 Harada N, Wiersema MJ, Wiersema LM. Endosonography-guided celiac plexus neurolysis. Gastrointest Endosc Clin N Am 1997;7:237-45.
162 Gunaratnam NT, Sarma AV, Norton ID, et al. A prospective study of EUS-guided celiac plexus neurolysis for pancreatic cancer pain. Gastrointest Endosc 2001;54:316-24.

163 Sakamoto H, Kitano M, Nishio T, et al. Value of computed tomography for evaluating the injection site in endosonography-guided celiac plexus neurolysis. Digestive Endoscopy 2006;18:206-11.

164 Tran QN, Urayama S, Meyers FJ. Endoscopic ultrasound-guided celiac plexus neurolysis for pancreatic cancer pain: a single-institution experience and review of the literature. J Support Oncol 2006;4:460-2. 464; discussion 463-4.

165 Wiechowska-Kozłowska A, Boer K, Wójcicki M, et al. The efficacy and safety of endoscopic ultrasound-guided celiac plexus neurolysis for treatment of pain in patients with pancreatic cancer. Gastroenterol Res Pract 2012;2012:1-5.

166 Seicean A, Cainap C, Gulei I, et al. Pain palliation by endoscopic ultrasoundguided celiac plexus neurolysis in patients with unresectable pancreatic cancer. $J$ Gastrointestin Liver Dis 2013;22:59-64.

167 Leblanc JK, Rawl S, Juan M, et al. Endoscopic ultrasound-guided celiac plexus neurolysis in pancreatic cancer: a prospective pilot study of safety using $10 \mathrm{~mL}$ versus $20 \mathrm{~mL}$ alcohol. Diagn Ther Endosc 2013;2013:1-6.

168 Gress F, Ciaccia D, Kiel J, et al. Endoscopic ultrasound (EUS) guided celiac plexus block (CB) for management of pain due to chronic pancreatitis (CP): a large single center experience. Gastrointest Endosc 1997;45:AB173.

169 Muscatiello N, Panella C, Pietrini L, et al. Complication of endoscopic ultrasoundguided celiac plexus neurolysis. Endoscopy 2006;38:858.

170 Ahmed HM, Friedman SE, Henriques HF, et al. End-organ ischemia as an unforeseen complication of endoscopic-ultrasound-guided celiac plexus neurolysis. Endoscopy 2009;41(Suppl 2):E218-9.

171 Lalueza A, López-Medrano F, del Palacio A, et al. Cladosporium macrocarpum brain abscess after endoscopic ultrasound-guided celiac plexus block. Endoscopy 2011:43(Suppl 2):E9-10.

172 Gimeno-García AZ, Elwassief A, Paquin SC, et al. Fatal complication after endoscopic ultrasound-guided celiac plexus neurolysis. Endoscopy 2012;44(Suppl 2):E267.

173 Fujii L, Clain JE, Morris JM, et al. Anterior spinal cord infarction with permanent paralysis following endoscopic ultrasound celiac plexus neurolysis. Endoscopy 2012;44(Suppl 2):E265-6.

174 Loeve US, Mortensen MB. Lethal necrosis and perforation of the stomach and the aorta after multiple EUS-guided celiac plexus neurolysis procedures in a patient with chronic pancreatitis. Gastrointest Endosc 2013;77:151-2

175 Jang HY, Cha SW, Lee BH, et al. Hepatic and splenic infarction and bowel ischemia following endoscopic ultrasound-guided celiac plexus neurolysis. Clin Endosc 2013:46:306-9.

176 Grimm H, Binmoeller KF, Soehendra N. Endosonography-guided drainage of a pancreatic pseudocyst. Gastrointest Endosc 1992;38:170-1.

177 Irani S, Ngamruengphong S, Teoh A, et al. Similar efficacies of endoscopic ultrasound gallbladder drainage with a lumen-apposing metal stent versus percutaneous transhepatic gallbladder drainage for acute cholecystitis. Clin Gastroenterol Hepatol 2017; 15:738-45

178 Tyberg A, Saumoy M, Sequeiros EV, et al. EUS-guided versus percutaneous gallbladder drainage: isn't it time to convert? J Clin Gastroenterol 2018;52:79-84.

179 Teoh AYB, Serna C, Penas I, et al. Endoscopic ultrasound-guided gallbladder drainage reduces adverse events compared with percutaneous cholecystostomy in patients who are unfit for cholecystectomy. Endoscopy 2017:49:130-8.

180 Teoh AY, Binmoeller KF, Lau JY. Single-step EUS-guided puncture and delivery of a lumen-apposing stent for gallbladder drainage using a novel cautery-tipped stent delivery system. Gastrointest Endosc 2014;80:1171.

181 Itoi T, Ishii K, Ikeuchi N, et al. Prospective evaluation of endoscopic ultrasonographyguided double-balloon-occluded gastrojejunostomy bypass (EPASS) for malignant gastric outlet obstruction. Gut 2016;65:193-5.

182 Khashab MA, Tieu AH, Azola A, et al. EUS-quided gastrojejunostomy for management of complete gastric outlet obstruction. Gastrointest Endosc 2015;82:745.

183 Catenacci DV, Chapman CG, Xu P, et al. Acquisition of portal venous circulating tumor cells from patients with pancreaticobiliary cancers by endoscopic ultrasound. Gastroenterology 2015;149:1794-803.

184 Lakhtakia S, Ramchandani M, Galasso D, et al. EUS-guided radiofrequency ablation for management of pancreatic insulinoma by using a novel needle electrode (with videos). Gastrointest Endosc 2016;83:234-9.

185 Song TJ, Seo DW, Lakhtakia S, et al. Initial experience of EUS-guided radiofrequency ablation of unresectable pancreatic cancer. Gastrointest Endosc 2016;83:440-3.

186 Shekelle PG, Park RE, Kahan JP, et al. Sensitivity and specificity of the RAND/ UCLA appropriateness method to identify the overuse and underuse of coronary revascularization and hysterectomy. J Clin Epidemiol 2001:54:1004-10.

187 Hemingway H, Crook AM, Banerjee S, et al. Hypothetical ratings of coronary angiography appropriateness: are they associated with actual angiographic findings, mortality, and revascularisation rate? The ACRE study. Heart 2001;85:672-9. 